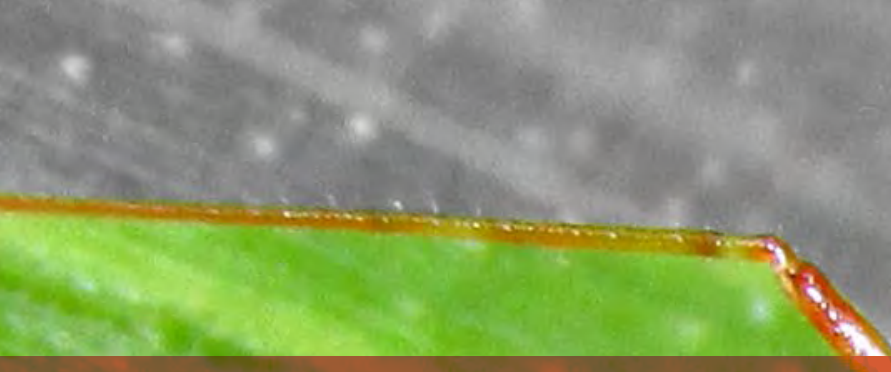

\title{
Control natural factores bióticos
}

\section{Luis Miguel Constantino*}

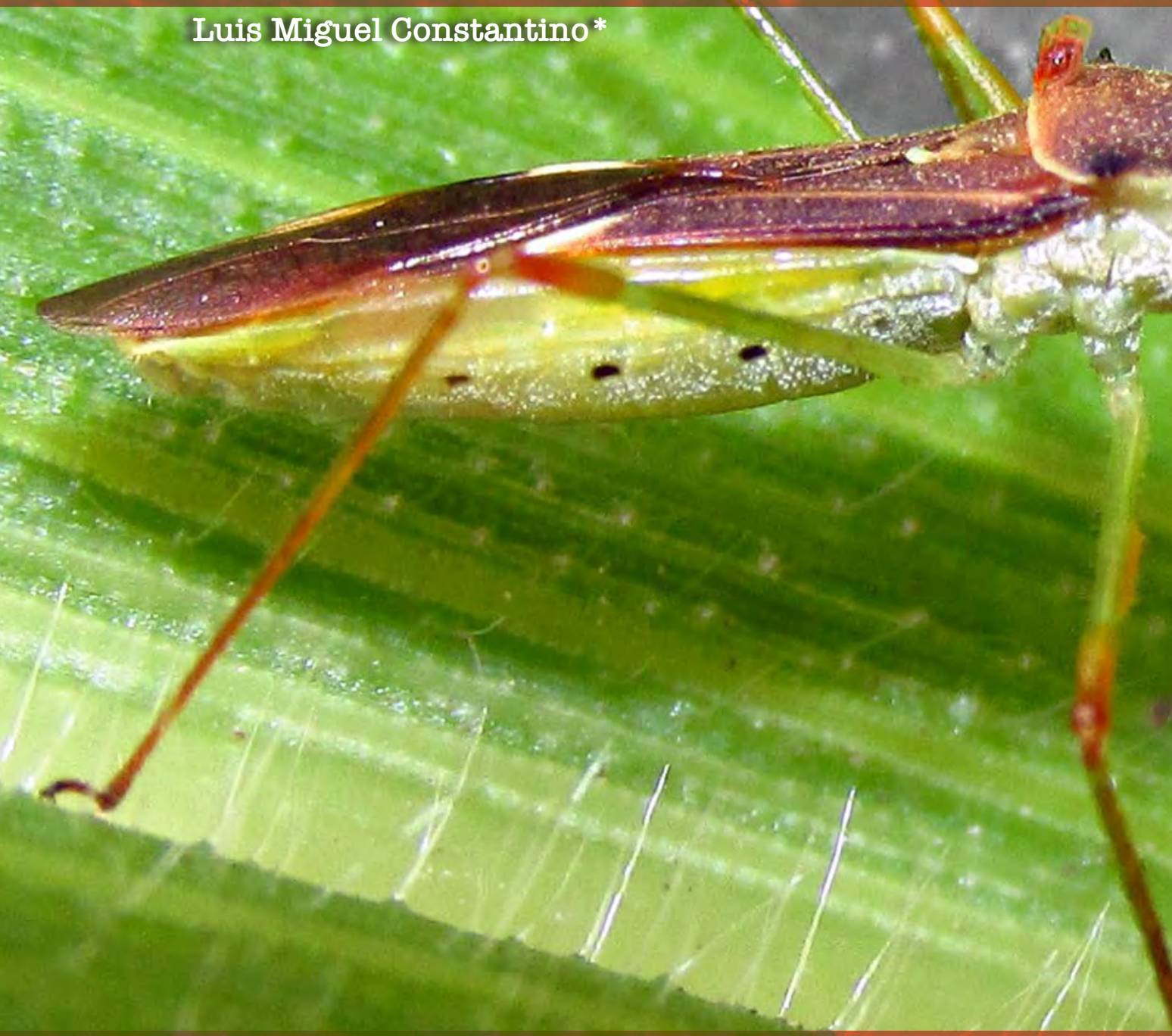

*Investigador Científico II, Disciplina de Entomología, Centro Nacional de Investigaciones de Café https://orcid.org/0000-0001-8117-5803

Como citar:

Constantino, L. M. (2020). El control biológico natural. En P. Benavides Machado \&e C. E. Góngora (Eds.), El Control Natural de Insectos en el Ecosistema Cafetero Colombiano (36-67). Cenicafé.

https://doi.org/10.38141/10791/0001_3

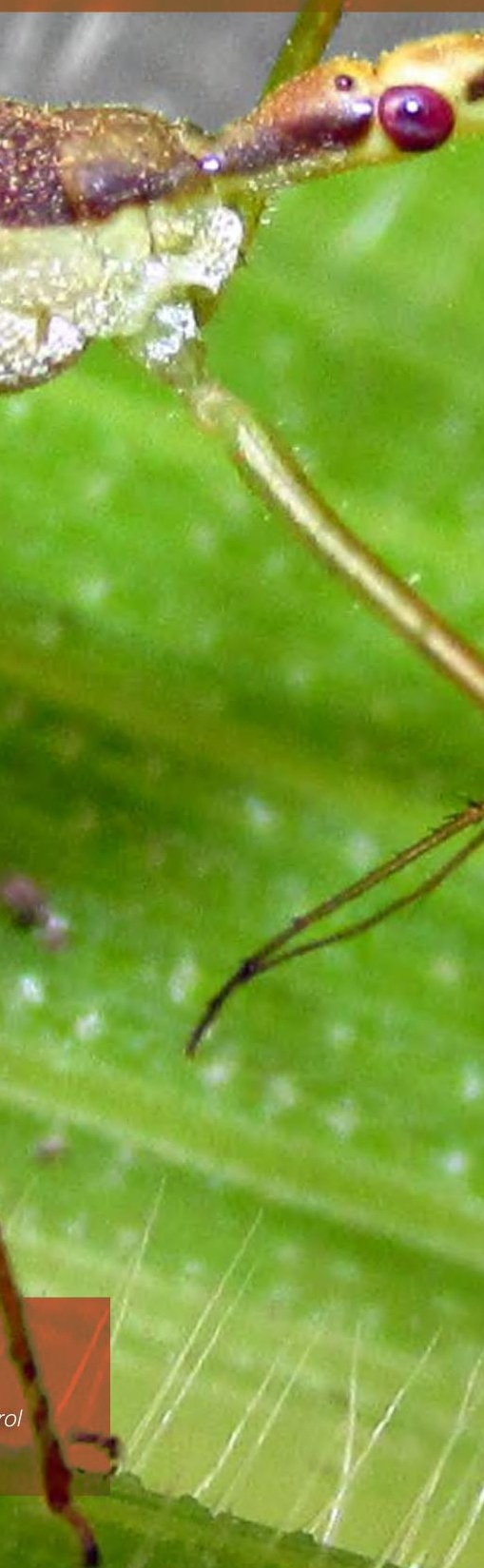




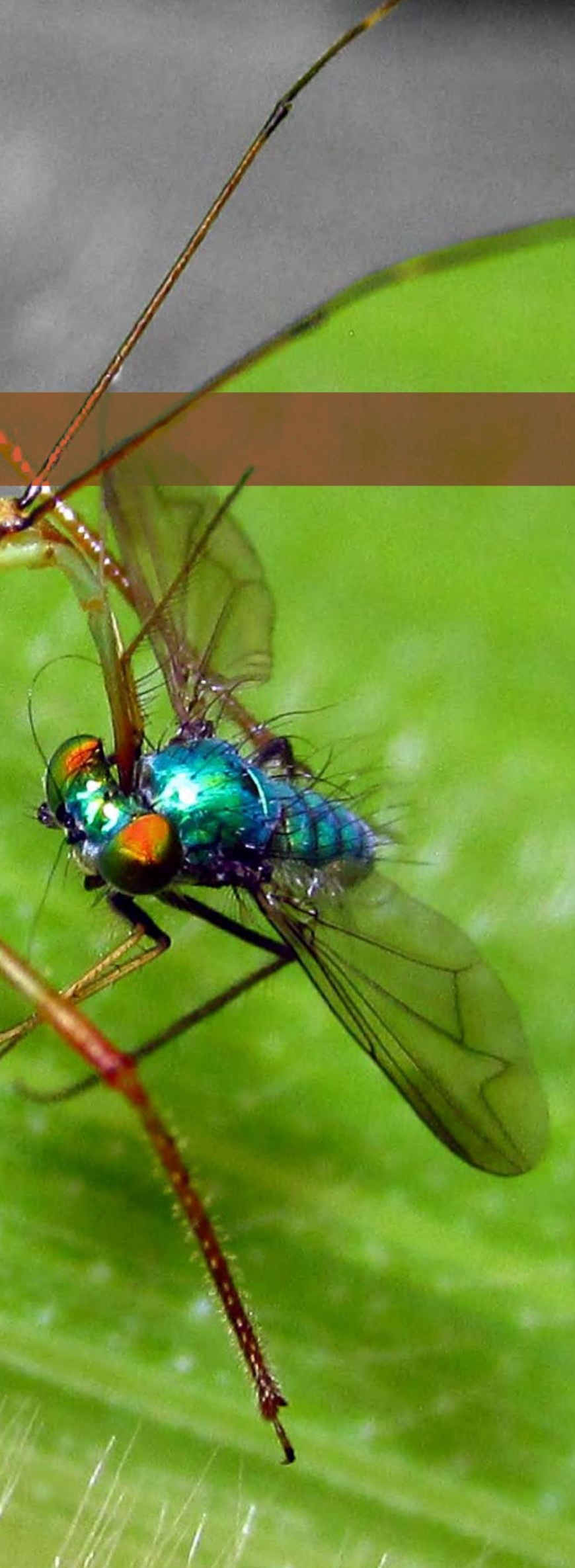

Rradicionalmente el control biológico natural se ha definido como la acción de parasitoides, depredadores y patógenos de forma espontánea, en el mantenimiento de la densidad de un organismo a un nivel bajo, como consecuencia de la acción de factores tanto bióticos (enemigos naturales) como abióticos (factores climáticos), sin la intervención del hombre (De Bach, 1964). Sin embargo, es importante diferenciarlo del control biológico, que es la manipulación de enemigos naturales por el hombre para mantener las poblaciones de plagas a niveles más bajos de los que se producirían en ausencia de ellos (Van den Bosch \& Messenger, 1973).

El agroecosistema cafetero de Colombia se caracteriza por presentar alta diversidad de fauna y flora, al estar ubicado en la franja ecuatorial de la región neotropical en el Norte de Suramérica, dividido por tres cordilleras y cadenas montañosas de la región Andina, y en un rango altitudinal amplio, apto para el cultivo de café, que va desde los 1.000 hasta los 2.200 metros de altitud. Debido a la estrecha relación que existe entre las plantas y los insectos, el alto porcentaje de endemismo de plantas en los Andes tropicales (aproximadamente la mitad de las especies) sugiere un nivel alto de diversidad y endemismo de insectos (Myers et al., 2000; Larsen et al., 2012).

Estos insectos fitófagos, en su mayoría, interactúan con las plantas hospedantes que les sirven de alimento, refugio y sitio de reproducción. A su vez, estos insectos actúan en la cadena trófica de los seres vivos como fuente de alimento, ya sea en forma de presas o como huésped para los enemigos naturales (depredadores y parasitoides) que los mantienen bajo control. Es decir, cada planta y animal en el agroecosistema cafetero tienen una función ecológica específica y juegan un papel importante en el sostenimiento de la biodiversidad y en el mantenimiento del equilibrio ecológico natural. En los ecosistemas, las poblaciones tienen límites para su crecimiento, es decir, no pueden crecer infinitamente ya que al final

El Control Natural de Insectos en el Ecosistema Cafetero Colombiano 
se alcanza el máximo tamaño poblacional que impone el medio ambiente y la disponibilidad de recursos alimenticios; es por eso que los factores que regulan el crecimiento poblacional se dividen en dos grupos: los que dependen de la densidad de población y los que son independientes de ella. Este capítulo se enfocará en los factores dependientes de la densidad poblacional.

\section{Factores dependientes de la densidadpoblacional}

Los factores dependientes de la densidad son deorigen biótico, generados por los organismos vivos y producen efectos inversamente proporcionales al tamaño de la población. Estos aumentan en efectividad conforme aumenta la población, es decir, controlan el crecimiento de la población. Por ejemplo, el caso de los parasitoides, depredadores y enfermedades que regulan la población de un insecto plaga en un agroecosistema.

En el agroecosistema cafetero estos eventos de control natural de plagas ocurren de forma espontánea y están influenciados por la disponibilidad de recursos alimenticios, las condiciones climáticas y las prácticas de manejo agronómico, que pueden favorecer el incremento o decrecimiento de las poblaciones de insectos en un momento dado. Por ejemplo, las prácticas agronómicas inadecuadas (uso excesivo y generalizado de plaguicidas) generan desequilibrios ecológicos al eliminar la fauna benéfica y favorecen el resurgimiento de plagas secundarias a niveles poblacionales altos.

\section{Control natural con parasitoides}

La mayoría de los insectos que parasitan a otros insectos se les conoce como parasitoides. A diferencia de los parásitos verdaderos, los parasitoides matan a sus hospedantes al final del ciclo, cuando completan su desarrollo en un solo huésped (Waage \& Greathead, 1986; Godfray, 1994). Son parásitos solamente en su estado inmaduro (larval) y llevan una vida libre en su estado adulto. Usualmente consumen todo o casi todo el cuerpo de su huésped y luego empupan, ya sea al interior o al exterior del mismo. La mayoría de los parasitoides pertenecen a los órdenes Hymenoptera y Diptera, y unos pocos son Coleoptera. Veintiséis familias de parasitoides reportados por Clausen (1962) y Greathead (1986) son usados frecuentemente en control biológico y pertenecen a las familias Trichogrammatidae, Eulophidae, Chalcididae, Scelionidae, Braconidae, Ichneumonidae, Eulophidae, Pteromalidae, Encyrtidae, Aphelinidae (Hymenoptera), y Tachinidae (Diptera).

\section{Categorias de los parasitoides}

Los parasitoides pueden categorizarse como ectoparasitoides, los cuales se alimentan externamente de sus huéspedes, y como endoparasitoides, que se alimentan internamente. Dependiendo de la forma de parasitar pueden clasificarse como koinobiontes o idiobiontes, dependiendo del lugar donde se desarrollen: dentro del huésped vivo, en huéspedes muertos o paralizados (Gauld \& Bolton, 1996). En el caso de los parasitoides koinobiontes, al momento de realizarse la oviposición, la hembra del parasitoide no mata al insecto hospedante y en muchos casos no lo paralizan, este sigue alimentándose y desarrollándose. Para lograr completar su desarrollo, los koinobiontes evitan alimentarse de los órganos vitales del huésped para no matarlo. La larva del parasitoide, una vez completa su desarrollo, le causa la muerte al hospedante cuando emerge o lo consume totalmente.

En el caso de los parasitoides idiobiontes, estos inyectan sustancias que paralizan o matan a su hospedante al realizar la oviposición. El objetivo es detener su desarrollo y permitir que la larva del parasitoide pueda alimentarse de él hasta completar su desarrollo.

Los endoparasitoides idiobiontes pueden parasitarhuevos, larvas, pupasy adultos de varias 
clases de insectos. Por ejemplo, las especies de Trichogramma (Trichogrammatidae), Telenomus (Scelionidae) y Ooencyrtus (Encyrtidae) se especializan en parasitar huevos de lepidópteros y hemípteros principalmente, con rangos de hospedantes más amplios que los parasitoides de larvas, por lo que son utilizados en programas de control biológico de insectos plagas en cultivos agrícolas. En el caso de algunas avispas que parasitan larvas de lepidópteros, las hembras inyectan con el huevo un polidnavirus (Polydnaviridae) simbionte (icnovirus) presente en la familia Ichneumonidae y (bracovirus) en avispas Braconidae; una vez insertados los huevos en la larva del lepidóptero, el virus infecta las células del insecto huésped. La principal función de los polidnavirus es suprimir el sistema inmune del hospedante, por consecuencia, las células de defensa (o hemocitos) no pueden encapsular los huevos o larvas del parasitoide (Rodríguez \& Beckage, 2006).

Una vez completado el ciclo de desarrollo de los estados inmaduros, el parasitoide adulto emerge de la pupa y se inicia así la próxima generación, buscando activamente nuevos huéspedes en los cuales ovipositar. La mayoría de los parasitoides adultos requieren de alimento suplementario como miel, polen o néctar (Bacca et al., 2012). Muchos se alimentan de los fluidos del cuerpo de sus huéspedes y otros requieren sólo agua en estado adulto (De Bach \& Rosen, 1991; Van Driesche et al., 2007; Bacca et al., 2012).

Los parasitoides pueden tener una generación (univoltinos) o dos o más (multivoltinos) por cada uno de los huéspedes. El ciclo de vida de los parasitoides es usualmente corto, desde diez días hasta cuatro semanas. El patrón de maduración de los huevos durante la vida de un parasitoide afecta la manera potencial en que el parasitoide puede ser usado en control biológico. Por ejemplo, las especies proovigénicas ya emergen con el suministro de huevos para toda su vida, permitiendo puestas masivas y un ataque rápido a múltiples hospedantes, factor muy requerido para su empleo en control biológico. Por el contrario, los huevos de las especies sinovigénicas se desarrollan gradualmente durante la vida de la hembra (Van Driesche et al., 2007; Van Driesche \& Bellows Jr, 1996). Estas condiciones son importantes a la hora de seleccionar un buen candidato para un programa de control biológico.

\section{Localización del hospedante y oviposición}

Un parasitoide recién emergido puede encontrarse lejos de su hospedante potencial y debe tener una buena y eficiente capacidad de búsqueda de su huésped. El parasitoide responde a diversos estímulos del hábitat y del hospedante para la aceptación del mismo. Para la localización del hábitat, el parasitoide responde a diversos factores ambientales como humedad, temperatura, sombrío, tipo de vegetación y sustancias químicas (semioquímicos), asociados a las plantas de las que se alimenta el huésped. Una vez localizado el hábitat, el parasitoide detecta a sus hospedantes mediante señales visuales, físicas o químicas presentes (Gauld \& Bolton, 1996).

Los semioquímicos o kairomonas son sustancias químicas percibidas por los parasitoides desde largas distancias 0 por contacto directo para poder ubicar a su huésped. Generalmente se encuentran en los excrementos, saliva, cutícula y huevos del huésped. El parasitoide una vez percibe estas señales se posa sobre la planta donde se encuentra su hospedante y utiliza los sensores del olfato ubicados en sus antenas, para rastrearlo en la planta, moviendo y barriendo las antenas de lado a lado sobre el follaje hasta tocar y encontrarlo a él o a sus rastros (Vinson, 1975, Vinson, 1981). Igualmente, utilizan ciertos estímulos físicos y sensoriales para la localización del huésped como la visión, el sonido y las vibraciones y movimientos que hacen las larvas del hospedante, ya sea dentro de las ramas o tallos si se tratan de larvas de barrenadores, o por el movimiento, vibración o sonidos que hacen las larvas sobre el follaje cuando están masticando (Gauld \& Bolton, 1996). 


\section{Tipos de parasitismo}

Existen varios tipos de parasitismo de acuerdo con las características de desarrollo sobre el huésped, que se describen a continuación (Figura 7).

\section{Parasitismo solitario y gregario}

Según el número de parasitoides por huésped, estos pueden clasificarse en solitarios, si un solo parasitoide se alimenta de un solo estado, o gregarios si son varios parasitoides los que se alimentan y completan su desarrollo del huésped. Un buen ejemplo de parasitimo gregario es el del parasitoide Cotesia congregata de la familia Braconidae, que parasita al gusano cachón del tabaco Manduca sexta (Figuras 7 B y 7 C).

A diferencia de los parasitoides solitarios que utilizan todo el huésped para completar su desarrollo, los parasitoides gregarios normalmente atacan hospedantes grandes para sostener el desarrollo de varias larvas del parasitoide. Generalmente, los adultos de los parasitoides gregarios son pequeños, mientras que los solitarios son grandes. El parasitismo gregario es el resultado de oviposiciones múltiples, depositados por la hembra sobre un solo huésped (Askew \& Shaw, 1986).

\section{Parasitismo poliembriónico}

El huevo depositado en el huésped se divide asexualmente produciendo multitud de nuevos individuos, un proceso conocido como poliembrionía, condición en la que dos o mas embriones se desarrollan de un solo huevo fertilizado (Segoli et al., 2010).

Un buen ejemplo de esto es la avispa Copidosoma truncatellum de la familia Encyrtidae, un parasitoide específico del gusano falso medidor Chrysodeixis includens y Trichoplusia ni (Lepidoptera: Noctuidae) sobre los cuales la avispa parasitoide coloca un solo huevo en el cuerpo de la larva del huésped, del cual se originan hasta 2.500 individuos, todos clones genéticamente idénticos a su madre (Figura $7 \mathrm{E}$ ).

\section{Multiparasitismo}

Es la presencia de dos o más individuos de diferentes especies de parasitoides en un mismo huésped. En este caso la larva de la especie más desarrollada o de mayor tamaño elimina las larvas de la especie menor, para evitar competencia por espacio y alimento en el huésped. Para evitar competencia, la mayoría de parasitoides marcan con señales odoríficas su huésped para evitar que otras avispas de su misma especie o especies diferentes ovipositen sobre su presa (Gauld \& Bolton, 1996).

\section{Superparasitismo}

Las hembras de la misma especie de parasitoide ponen más de un huevo en el mismo hospedante. Este es un caso muy frecuente en varios géneros de la familia Pteromalidae, Braconidae, Encyrtidae, Eulophidae y Trichogrammatidae, y corresponde a especies pequeñas de parasitoides en presas grandes o medianas, que permiten el sostenimiento y desarrollo de multitud de parasitoides. Un ejemplo en café es la avispa Phymastichus coffea, endoparasitoide primario de adultos de la broca del café Hypothenemus hampei (Jaramillo et al., 2006).

\section{Hiperparasitismo}

Ocurre cuando un parasitoide parasita a otro parasitoide. Los hiperparasitoides también se conocen como parasitoides secundarios. Hay casos de parasitoides terciarios. Hace parte de la cadena trófica de los seres vivos, en las que cada especie tiene uno o varios enemigos naturales específicos. Estos se pueden dividir en:

- Hiperparasitoides facultativos: la hembra oviposita antes de que llegue el parasitoide primario y espera a que este sea parasitado para atacar su hospedante parasitoide.

- Hiperparasitoides obligados: los hiperparasitoides sólo pueden desarrollarse 
como parasitoides de parasitoides, y deben encontrar un hospedante previamente parasitado, como el caso de la avispa Aphanogmus dictynna (Hymenoptera: Ceraphronidae) parasitoide primario de la avispa Prorops nasuta (Hymenoptera: Bethylidae) que parasita a la broca del café (Buffington, \& Polaszek, 2009).

\section{Control natural con depredadores}

Los depredadores son especies que consumen y matan directamente a su presa alimentándose de todos los estados de desarrollo (huevos, larvas, pupas y adultos) de un gran número de individuos y especies, es decir, los depredadores son especies generalistas (Altieri \& Nicholls, 1999). Esto es una desventaja frente a los parasitoides, al no ser específicos, porque pueden atacar también especies benéficas, como por ejemplo el caso de las avispas de la familia Vespidae que depredan larvas del minador de la hoja del cafeto Leucoptera coffeella que están parasitadas por avispas Eulophidae. En este caso el depredador consume y mata las larvas del minador y las larvas de los parasitoides que se encuentran en el interior o exterior de las larvas parasitadas del minador (Figura 9). Otro ejemplo es el del coccinélido Cycloneda sanguinea y el áfido Myzus persicae, que pueden estar parasitados por la avispa Aphidius colemani (Hymenoptera: Braconidae, Aphidiinae).

Una de las características de los depredadores es que generalmente son de mayor tamaño al de sus presas y se alimentan de muchos insectos individuales. Las hembras, por lo general colocan los huevos cerca del alimento, nunca sobre este. Los insectos depredadores pueden ser masticadores o chupadores. Es el caso de los depredadores provistos de mandíbulas que matan a sus presas atrapándolas con sus mandíbulas y las mastican para consumirlas. Algunos ejemplos son las hormigas cazadoras (Hymenoptera: Formicidae), algunos coleópteros depredadores (Coleoptera) de las familias Carabidae, Silvanidae, Coccinelidae, Cleridae, los insectos mantis religiosa (Mantodea), avispas de la familia Vespidae (Hymenoptera), las tijeretas Dermaptera (Foriculidae), los mantíspidos (Neuroptera: Mantispidae) y las chrisopas Chrysoperla sp. (Neuroptera: Chrysoperlidae) (Clausen, 1962; Nicholls, 2008). En estos últimos, las larvas tiene un par de mandíbulas grandes en forma de pinza con las que sujetan a sus presas y le inyectan enzimas dentro del cuerpo para disolver sus órganos internos, con el fin de poder absorber el contenido del cuerpo de su presa; mientras que los adultos se alimentan de néctar, polen y sustancias azucaradas en las plantas. Otros insectos depredadores, carecen de mandíbulas y tienen estiletes que utilizan para chupar el contenido interno (hemolinfa) de sus presas, como el caso de las chinches (Hemiptera) pertenecientes a las familias Reduviidae, Anthocoridae y Pentatomidae (Figuras 7, 8 y 10). Algunas familias de moscas (Diptera) de la familia Asilidae, los adultos capturan sus presas en el vuelo y en las moscas de la familia Syrphidae, las larvas se alimentan de insectos de cuerpo blando como pulgones, escamas, cochinillas, ácaros, thrips y huevos y ninfas de mosca blanca. Finalmente, las arañas (Araneae) y los ácaros depredadores de la familia Phytoseidae succionan la hemolinfa de su presas con los cheliceros. Muchos de estos ácaros depredadores se refugian en las domacias que presentan las hojas de café en el envés a lo largo de la nervadura central. Las domacias son orificios naturales que sirven de refugio a los ácaros depredadores (Gil et al., 2013).

Finalmente, los insectos depredadores pueden clasificarse en polífagos, cuando se alimentan de especies pertenecientes a diversas familias y especies de plagas, en oligófagos cuando se alimentan de presas que pertenecen a varios géneros y especies de una misma familia, y en monófagos cuando se alimentan de especies específicas de un solo género. 

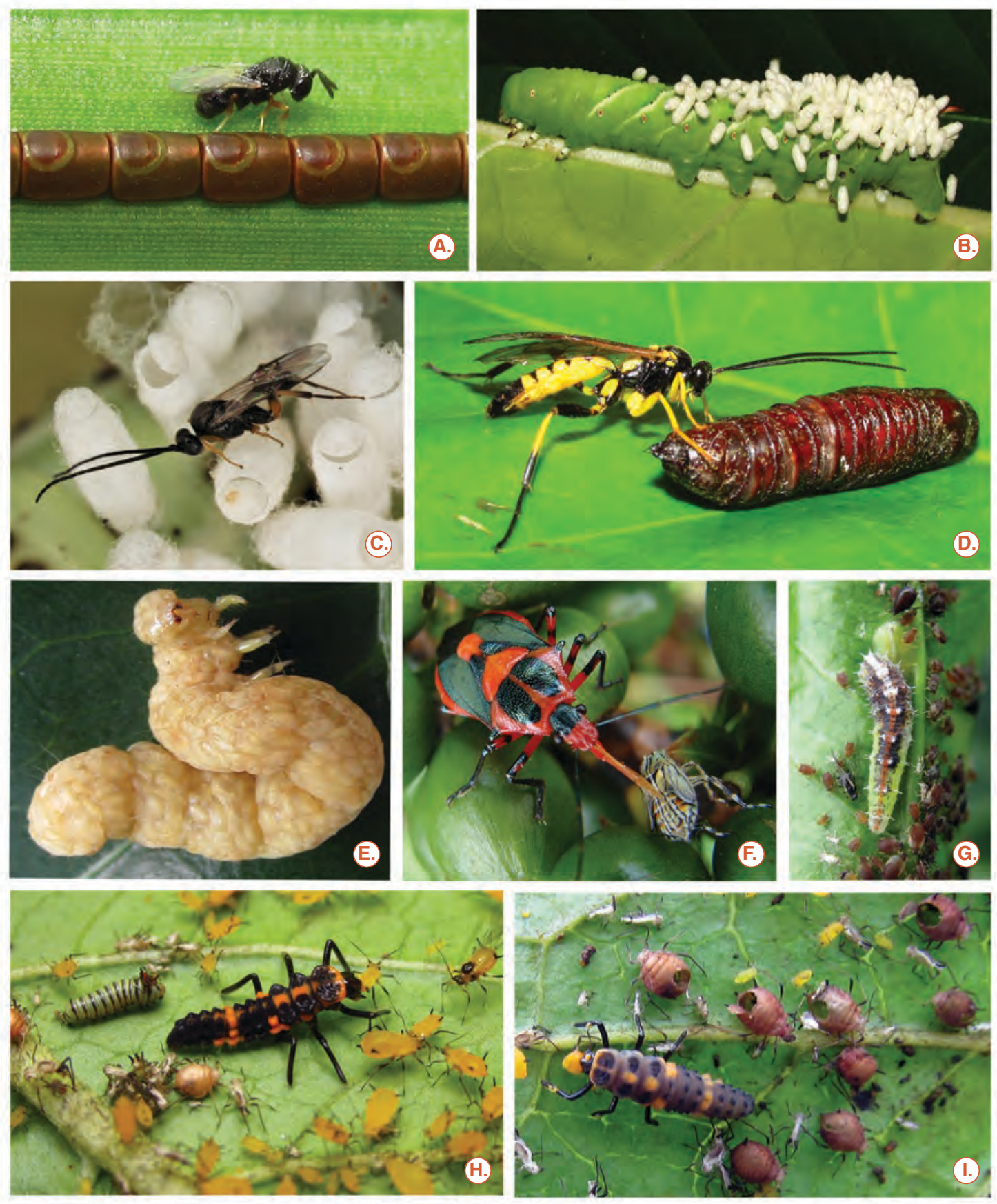

Figura \%

Diferentes tipos de parasitoides y depredadores de insectos plaga. A. Gryon variicornis (Platygastridae: Scelioninae) endoparasitoide idiobionte de huevos de Leptoglossus zonatus. B-C. Cotesia congregata (Braconidae) endoparsitoide koinobionte gregario en larva de Manduca sexta. D. Pimpla sp. (Ichneumonidae) parasitoide solitario de pupas de Chrysomima semilutearia. E. Parasitismo poliembriónico de Copidosoma truncatellum (Encyrtidae) sobre larva de Chrysodeixis includens F. Euthyrhynchus floridanus (Pentatomidae) depredando una ninfa de cigarrita del café Aethalion reticulatum. G. larva de Syrphidae depredando ninfas de pulgón negro Toxoptera aurantii. $\mathbf{H}$. Larva de Cycloneda sanguinea (Coccinelidae) depredando Aphis nerii. I. Momias de pulgón amarillo Aphis nerii parasitadas por Lysiphlebus testaceipes (Braconidae). 


\section{Control biológico por conservación}

\section{Mantenimiento de la fauna benéfica en el cafetal}

El control biológico por conservación se basa en la modificación del medio ambiente o de las prácticas agronómicas existentes en un cultivo para protegery aumentar los enemigos naturales específicos $u$ otros organismos con la finalidad de reducir el efecto de las plagas (De Bach, 1964). El control biológico por conservación se diferencia de otras estrategias de control biológico dado que no se realizan liberaciones de enemigos naturales, sino que busca establecer, mediante la aplicación de determinados métodos, un entorno ambiental en el que se desarrolle el cultivo (Altieri \& Nicholls, 1999; Paredes et al., 2013). La aplicación de estos métodos no ejerce por sí misma el control biológico de las plagas, sino que promueve la abundancia y diversidad de los enemigos naturales ya presentes en el agro ecosistema. El mejor ejemplo del beneficio del control biológico por conservación en los cafetales colombianos son los lotes infestados con minador de la hoja del café L. coffeella; se ha podido demostrar que los lotes de café en levante, de menos de 18 meses, en épocas secas son atacados por el minador cuando las arvenses nobles fueron eliminadas por completo, mediante el uso de herbicidas aplicados de forma generalizada. Esta práctica de eliminar por completo las arvenses nobles que producen flores que proporcionan néctar y refugio a la fauna benéfica, ocasiona que los parasitoides y depredadores del minador desaparezcan del cafetal al no tener los adultos otra opción de alimento para subsistir, ocasionando la migración de la fauna benéfica fuera del lote. Al no tener el minador sus enemigos naturales presentes, las poblaciones de minador se incrementan considerablemente. Sin embargo, cuando se hace una desyerba manual en el plato del árbol y se dejan coberturas nobles en las calles del cafetal, el equilibrio ecológico se restablece y las poblaciones de minador se disminuyen logrando mantener las poblaciones de la plaga bajo control natural (David-Rueda et al., 2016).

Entre las prácticas de control biológico por conservación que pueden implementarse en Colombia dentro del manejo integrado de la broca, el minador, la arañita roja, la chinche de la chamusquina del café y las cochinillas de la raíz, se encuentra el mantenimiento de nichos ecológicos adecuados para los enemigos naturales como las franjas de vegetación de arvenses nobles en las calles y bordes del cafetal que provean de néctar y refugio a los adultos de los parasitoides y depredadores. Igualmente, el permitir vegetación arbórea en la periferia de los cultivos o sombrío estratificado que sirva como sitios de anidamiento y refugio de las hormigas en localidades con sistemas agroforestales. En cultivos a libre exposición, el uso de sustratos para anidación de las hormigas (ramas secas, ramas de bambú, canutos de guadua) para que puedan establecerse y formar colonias, logrando que permanezcan en los lotes de café.

\section{Enemigos naturales de algunos artrópodos fitófagos del cultivo del café en Colombia}

\section{Parasitoides y depredadores de la broca del café Hypothenemus hampei (Coleoptera: Curculionidae: Scolytinae)}

La broca del café es el principal problema entomológico para la caficultura en Colombia. Uno de los componentes del manejo integrado de esta plaga es el control biológico mediante el uso de parasitoides de origen africano, de 
los cuales tres especies se introdujeron, criaron y liberaron en Colombia, con el objetivo de establecerlas en los cafetales para regular las poblaciones de la broca. Estas especies fueron la avispa de Uganda, $P$. nasuta (Hymenoptera: Bethylidae), en el año 1989-1990, la avispa de Costa de Marfil, Cephalonomia stephanoderis (Hymenoptera: Bethylidae), en 1989-1990, y la avispa de Togo, P. coffea (Hymenoptera: Eulophidae) en 1995 (Figura 8). De las tres especies se liberaron un total de 2.300 millones de adultos en cafetales de 17 departamentos del país (Benavides, 2008; Bacca, 2011; Maldonado \& Benavides, 2011) de las cuales $P$. nasuta se encuentra establecida en el país con niveles de parasitismo entre 1,5\% y 50,0\% (Maldonado \& Benavides, 2008). Hoy en día, existen laboratorios comerciales que mantienen estas tres especies de parasitoides para el control de la broca del café, las cuales están disponibles para los caficultores. En África central, su región de origen, la broca del café cuenta con varios enemigos naturales que regulan sus poblaciones como los parasitoides ya mencionados, la avispa Heterospilus coffeicola (Hymenoptera: Braconidae) y el depredador Karnyothrips flavipes (Thysanoptera: Phaelothripidae) (Bustillo et al., 2002; Benavides, 2008; Jaramillo, 2008; Vega et al., 2009). En América hay reportes de los parasitoides C. hyalinipennis (Hymenoptera: Bethylidae) en México (Pérez-Lachaud \& Hardy, 1999) y Cryptoxilos sp. (Hymenoptera: Braconidae) en Colombia (Bustillo et al., 2002), pero este último no ha vuelto a ser reportado atacando la broca del café.

La broca del café se reproduce en los frutos que quedan después de las cosechas, siendo estos los focos para infestaciones futuras. En Colombia se han reportado depredadores nativos atacando estados inmaduros y adultos de broca dentro de los frutos de café que se quedan después de las cosechas (Vera et al., 2007; Benavides, Vera, \& Gil, 2008; Cenicafé, 2013). Los insectos parasitoides y algunos depredadores que se han encontrado dentro de los frutos brocados de café, tienen la habilidad de penetrar por el orificio de entrada que hace la broca en el fruto y buscar a través de las galerías y túneles los estados inmaduros y adultos para parasitarlos o depredarlos.
Actualmente, las especies más importantes depredando broca pertenecen a las familias Formicidae (Hymenoptera), Anthocoridae (Hemiptera) y Silvanidae (Coleoptera) (Figura 8). Diez especies de hormigas en los géneros Crematogaster, Solenopsis, Pheidole, Wasmannia, Brachymyrmex, Pseudomyrmex, Mycocepurus, Dorymirmex y Prenolepis se han observado dentro de frutos brocados y en los orificios de entrada, depredando estados inmaduros de broca (Bustillo et al., 2002; Gallego \& Armbrecht, 2005; Vélez et al., 2006; Philpott \& Armbrecht, 2006; Vera et al., 2007; Benavides et al., 2008); durante el secado de café pergamino se tienen registradas a Pheidole, Solenopsis y Dorymirmex depredando adultos de broca (Vélez et al., 2006).

Recientemente, Constantino et al. (2017) evaluaron la capacidad depredadora de tres especies de hormigas en el campo en cultivos de café a libre exposición solar, utilizando café pergamino seco brocado, con diez unidades experimentales por especie, las cuales consistieron en una malla conteniendo diez granos de café brocado, con 20 días de infestación, amarrados en árboles de café con presencia de nidos activos de hormigas. Por cada unidad experimental se tuvo un testigo absoluto con exclusión de hormigas. Se evaluó el número de estados de broca vivos, 24 horas después de montados los tratamientos. Los resultados mostraron que Solenopsis picea fue la especie que depredó mayor cantidad de estados de broca, disminuyendo hasta 84,5\% de los estados biológicos respecto al testigo, seguida de Tapinoma melanocephalum y Crematogaster crinosa con 48,4\% y 40,7\%, respectivamente. El promedio de adultos de $S$. picea hallados dentro de los granos brocados fue de 25,9 \pm 14,2 y 3,0 0 0,6 de $T$. melanocephalum, lo que confirma que estas especies son capaces de entrar por el orificio de entrada que hace la broca a los granos de café. Por el contrario, no se observó a $C$. crinosa dentro de los granos de café, por su mayor tamaño corporal, restringiéndose esta especie a depredar solo estados de broca que se encuentran cerca del orificio de entrada o en el canal de penetración. Estos 

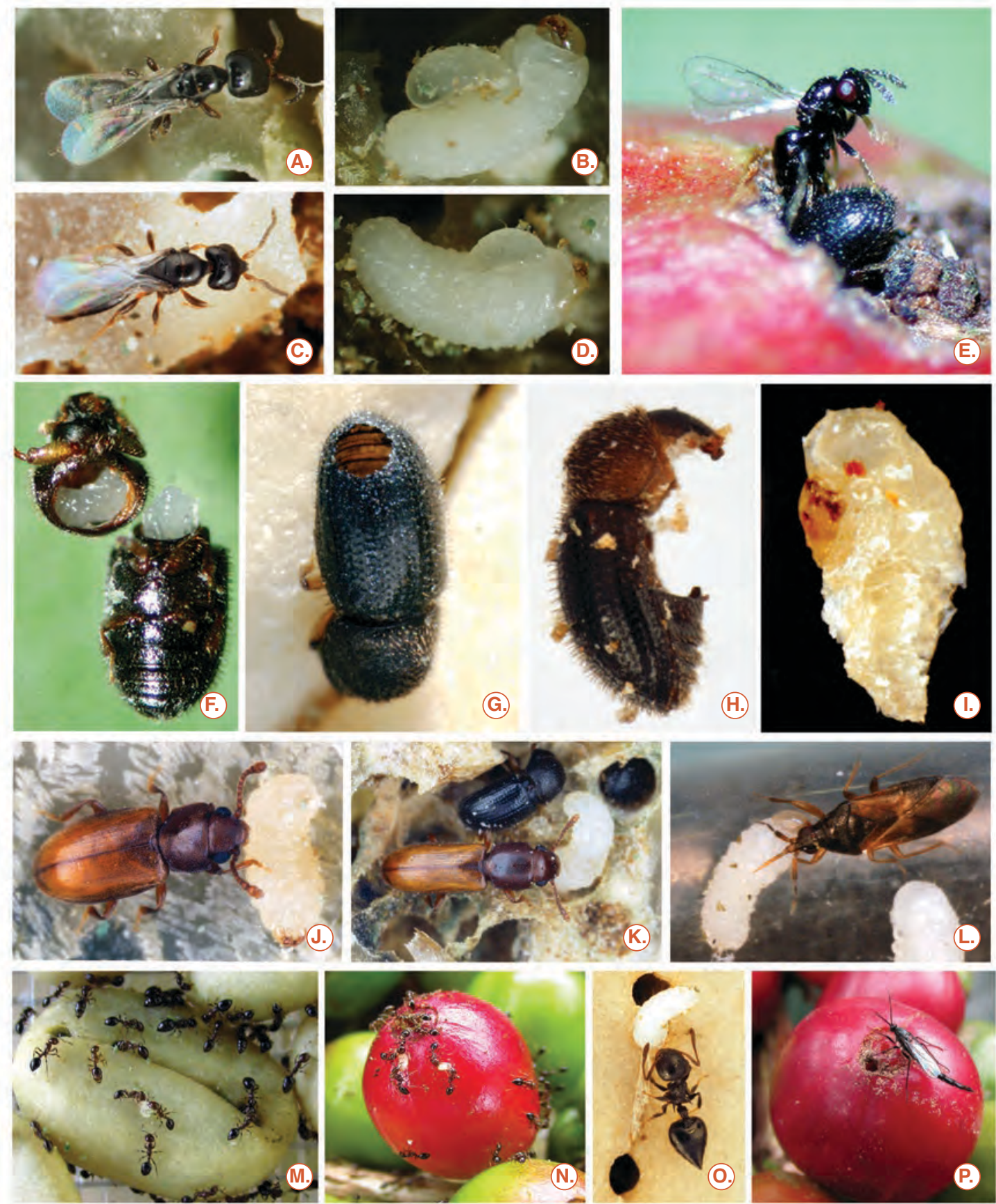

Figura 8.

Parasitoides y depredadores en el control de la broca del café Hypothenemus hampei en Colombia. A-B. Adulto y larva de Cephalonomia stephanoderis. C-D. Adulto y larva de Prorops nasuta. E. Phymastichus coffea parasitando un adulto de broca. F-G. Brocas parasitadas por Phymastichus coffea con orificio circular de salida del parasitoide. H-I. Adulto y larva de broca depredada por Ahasverus advena. J. Ahasverus advena consumiendo larva de broca. K. Cathartus quadricollis depredando larva de broca. L. Xylocoris sp. depredando una larva de broca del café. M-N. Solenopsis picea depredando larvas de broca en grano y fruto de café. O. Crematogaster crinosa depredando larva de broca. P. Lycoriella sp. ovipositando sobre fruto brocado.

El Control Natural de Insectos en

el Ecosistema Cafetero Colombiano 
resultados muestran que $S$. picea tendría potencial como estrategia de control biológico por conservación en un programa de manejo integrado de la broca del café (Figura 8).

En los frutos sobremaduros y secos brocados del árbol y del suelo, que se quedan después de las cosechas, se han hallado hasta el momento un total de 38 especies de insectos depredadores, parasitoides y competidores de la broca del café, incluyendo dos especies de hongos entomopatógenos, Beauveria bassiana y Metarhizium anisopliae. Dos especies de coleópteros de la familia Silvanidae, antes Cucujidae, se han registrado dentro de las galerías y túneles en granos infestados de broca, siendo Cathartus quadricollis y Monanus sp. las dos especies identificadas (Bustillo et al., 2002; Vera et al., 2007; Cenicafé, 2013). Ambas especies fueron evaluadas por Vera et al. (2007), con pruebas de predación directa, ofreciéndoles estados inmaduros de broca en cajas de Petri, logrando porcentajes de depredación de broca mayores al 60\% a partir de adultos de C. quadricollis y Monanus sp. obtenidos de campo. Recientemente Cenicafé (2013) reportó a Ahasverus advena, Europs (Coleoptera: Silvanidae) y Xylocoris sp. (Hemiptera: Anthocoridae), depredando estados biológicos de broca en Colombia, las cuales no se tenían reportadas en el país atacando broca del café. La proporción porcentual de adultos de C. quadricollis hallados dentro de las galerías en frutos brocados de café en el campo fue de 17\% en el árbol y de $13 \%$ en el suelo, en localidades por debajo de $1.300 \mathrm{~m}$ de altitud. A. advena se encontró en el $15 \%$ de los frutos secos del árbol y en $10 \%$ en los frutos del suelo. Xylocoris sp (Hemiptera: Anthocoridae) se observó principalmente en el interior de frutos secos brocados del árbol en un 15\% en cultivos de café a libre exposición, en lotes donde no se habían aplicado insecticidas de síntesis química. A partir de estas observaciones, Cenicafé (2013) estableció crías en el laboratorio de dos especies de coleópteros de la familia Silvanidae, C. quadricollis y A. advena en diferentes sustratos y dietas para evaluarlos en el laboratorio y en el campo (Figura 8). Sobre este material de cría, Laiton et al. (2018) evaluaron la capacidad depredadora de $C$. quadricollis y $A$. advena sobre la broca del café en condiciones de laboratorio en Cenicafé utilizando café pergamino seco brocado, de 21 días de infestación, conteniendo en promedio ocho estados de broca por grano. Los resultados mostraron que los adultos de $A$. advena disminuyeron significativamente la broca dentro de las almendras, presentando valores hasta de 63,2\% menores con respecto al testigo y las larvas mostraron una disminución de hasta el 42,3\%. La capacidad depredadora de esta especie fue mayor cuando se utilizaron tres y cinco depredadores por grano brocado. De igual forma, los adultos de C. quadricollis disminuyeron la broca hasta un 46,2\% utilizando tres depredadores por grano y las larvas hasta un $69 \%$ utilizand o cinco depredadores por grano (Figura 8). Follett et al. (2016) en Hawái evaluaron la capacidad depredadora de adultos de $C$. quadricollis con pruebas de predación directa sobre estados biológicos de broca, donde se expusieron 20 estados de broca por cada tres depredadores adultos, obteniendo $77,5 \%$ de depredación en huevos, $55,0 \%$ en larvas, $53,0 \%$ en pupas y $15,5 \%$ en adultos.

Dentro del orden Hemiptera, familia Anthocoridae, Bustillo et al. (2002) encontraron ninfas y adultos de un género no identificado y dos especies pertenecientes a los géneros Calliodes y Scoloposcelis en los orificios de entrada y las galerías que construye la broca alimentándose de los estados inmaduros de esta. Vera et al. (2007) reportaron una especie del género Xylocoris sp. depredando estados inmaduros de broca. En la literatura se reporta a Xylocoris flavipes como un depredador generalista de plagas de granos almacenados entre las que se encuentran el gorgojo dentado de los granos Oryzaephilus surinamensis, la polilla india de la harina Plodia interpunctella, el gorgojo castaño de la harina Tribolium castaneum y la carcoma del tabaco Lasioderma serricorne (Le Cato \& Davis, 1973). Recientemente, Cenicafé (2013) encontró otra especie de Xylocoris sp. en frutos de café brocados depredando larvas de broca y estudió su ciclo de vida utilizando granos brocados infestados con estados 
inmaduros de broca. Las ninfas de Xylocoris sp. fueron capaces de penetrar por los orificios de entrada de la broca en busca de presas. En pruebas de laboratorio, ofreciéndoles estados biológicos de broca a los adultos de Xylocoris, se observó mayor preferencia hacia las larvas, obteniendo porcentajes de depredación de hasta el $65 \%$.

Los adultos de Xylocoris tienen un palpo labial largo compuesto de dos estiletes; se observó que los adultos de estos chinches depredadores una vez ubican a su presa, le insertan el estilete y le inyectan una enzima que paraliza al insecto en corto tiempo (Figura 8). Esta enzima digestiva licua el contenido interno del cuerpo de su presa, para poder succionar toda la hemolinfa de la presa. Las larvas de broca inyectadas y paralizadas adquieren una consistencia flácida y blanda al tacto, en menos de 12 horas. El punto de inserción del estilete sobre la presa se necrosa y se forma un hematoma en el cuerpo de la larva. Cuando la larva de la broca está completamente licuada en su interior, adquiere una coloración amarillenta y se revienta al tacto.

Con respecto a nematodos entomopatógenos, en Colombia se han evaluado varias especies contra la broca del café pertenecientes a los géneros Steinernema y Heterorhabditis de la familia Mermithidae. Todas las especies de nematodos entomopatógenos guardan una asociación simbiótica con varias especies de bacterias de los géneros Xenorhabdus spp. y Photorhabdus spp. involucradas en la patogénesis hacia larvas y adultos de broca, ya que estos nematodos son capaces de penetrar por los orificios de entrada que hace la broca en los frutos de café y parasitarla (López, 2008).

En los frutos de café brocados del árbol se han encontrado otros insectos que compiten con la broca del café por espacio y alimento, a estos se les denomina competidores y aunque no matan al hospedante, sí logran desplazar a la broca fuera del fruto de café. Un buen ejemplo de este caso es el de la mosca negra Lycoriella sp. (Diptera: Sciaridae) en el cual la mosca oviposita sobre frutos de café brocados. En estos frutos la mosca introduce su ovipositor en el orificio de entrada que hace la broca del café, colocando de dos a tres huevos por fruto. Una vez los huevos eclosionan, las larvas de Lycoriella penetran por las galerías de la broca y empiezan a alimentarse de los detritos y ripio que producen los adultos y larvas de la broca en la almendra de café. Las larvas de Lycoriella aceleran el proceso de descomposición de la almendra y la pulpa de café, ocasionando mortalidad de los estados inmaduros de la broca y el desplazamiento de los adultos fuera del fruto (Figura 8).

\section{Parasitoides y depredadores del minador de la hoja del café Leucoptera coffeella (Lepidoptera: Lyonetidae)}

El minador de las hojas del café es una especie estacional, que prevalece en períodos secos. La larva se alimenta exclusivamente de plantas de café (monófaga) y ocasiona el daño cuando consume la epidermis de la hoja, penetrando el mesófilo del tejido donde forma galerías irregulares. Estas lesiones se necrosan y se secan tornándose de color marrón. En la mayoría de los países cafeteros el control de L. coffeella ha estado fundamentado en el uso de insecticidas químicos, sin tener en cuenta el impacto ambiental y el efecto sobre la fauna benéfica asociada al cultivo, causando problemas de contaminación del agro ecosistema y la muerte de sus enemigos naturales (Fragoso et al., 2002; Carvalho et al., 2004). Adicionalmente, el uso de insecticidas organofosforados para el control de minador en países como Brasil, ha llevado a la aparición de insectos resistentes (Fragoso et al., 2003).

L. coffeella tiene reportadas 55 especies de enemigos naturales primarios en la región Neotropical, 43 de los cuales son parasitoides (Lomeli-Flores, 2007). El control biológico natural se presenta en Colombia, por más de 12 especies de avispas parasitoides de la familia Eulophidae que parasitan las larvas del minador, y por más de cinco especies de avispas depredadoras de la familia Vespidae (Constantino et al., 2011; David-Rueda et al., 2016).

El Control Natural de Insectos en el Ecosistema Cafetero Colombiano 
Los parasitoides de las larvas del minador presentes en Colombia pertenecen a diferentes especies de avispas de la familia Eulophidae, que se distinguen por presentar coloraciones con visos verdes o azules metalizados en todo el cuerpo (Figura 9). Los parasitoides usan estímulos químicos, olfativos, visuales y vibraciones, como señales para la búsqueda del huésped. Una vez la avispa se posa sobre las hojas y detecta la larva del minador, introduce su ovipositor en forma de aguja que perfora la epidermis de la hoja hasta alcanzar la larva para introducirle un huevo. Del huevo eclosiona una larva que, dependiendo de la especie, puede ser de tipo endoparasitoide o ectoparasitoide (Figura 9). Los parasitoides empupan dentro de la mina y se reconocen por el tono negro brillante y la forma de pupa de tipo exarata que muestran las partes del futuro adulto (Figura 9). Al cabo de unos 15 días después de haber completado su ciclo, las avispas emergen perforando orificios circulares pequeños en la superficie de la mina con sus mandíbulas. La mayoría de las especies de parasitoides emergen de las larvas de minador, solo una especie de Horismenus se observó emergiendo de las pupas de minador.

Las especies reportadas en Colombia de la familia Eulophidae parasitando larvas de minador son: Achrysocharoides sp., Cirrospilus sp., Closterocerus coffeellae, C. lividus, Eulophus sp., Horismenus cupreus, Horismenus sp. nov., Proacrias coffeae, Pnigalio sarasolai, Tetrastichus sp., Zagrammosoma multilineatum y Apleurotropis sp., y de la familia Braconidae Allobracon primus (Braconidae).

De acuerdo a Lomeli-Flores (2007) otras especies de la familia Eulophidae de Centro América y Suramérica no reportadas en Colombia son: Chrysocharis milleri (México), Chrysonotomyia sp. (México), Cirrospilus variegates (Nicaragua), Closterocerus cinctipennis (Cuba, Puerto Rico), C. flavicinctus (Brasil), C. leucopus (Perú), Derostenus sp. (Puerto Rico), Elachertus sp. (Brasil, México, Puerto Rico), Euderus lividus (Puerto Rico), Eulophus cemiostomatis (Brasil), Horismenus aeneicollis (Brasil), Microlycus sp. (Perú),
Miotropis sp. (México), Neochrysocharis arata (Perú), N. formosa (Puerto Rico), Pediobius sp. (Perú), Platocharis coffeae (Puerto Rico), Pnigalio elongatus, (México), Zagrammosoma lineaticeps (México) y Z. seini (Puerto Rico).

De la familia Braconidae se tienen reportados a Apanteles sp. (Guatemala), Bracon sp. (Guatemala), Mirax insularis, M. striata (Brasil), Orgilus niger, O. punctatus (Brasil), Stiropius letifer y S. reticulatus (Brasil).

En cuanto a hormigas (Hymenoptera: Formicidae), Lomeli-Flores (2007) reporta cinco especies de los géneros Crematogaster, Azteca, Camponotus y Cephalotes que depredan huevos, cinco especies de los géneros Camponotus y Pseudomyrmex que depredan larvas y nueve especies de los géneros Azteca, Camponotus, Leptothorax, Monomyrmex, Pseudomyrmex y Solenopsis que depredan pupas.

\section{Parasitoides y depredadores del saltamontes enmascarado del café Poecilocloeus coffeaphilus (Orthoptera: Acrididae: Proctolabinae)}

Poecilocloeus coffeaphilus es una especie de saltamontes endémico de zonas boscosas en los municipios de Concordia, Salgar y Betulia, en el Suroeste del departamento de Antioquia, en el flanco Oriental de la cordillera Occidental de Colombia, en un rango altitudinal de 1.600 a $1.800 \mathrm{~m}$. El movimiento de los saltamontes ocurre entre los bosques circundantes y el cultivo de café. Es de hábitos polífagos y se alimenta de un amplio número de plantas, entre las que se destacan especies forestales como el cascarillo Ladenbergia oblongifolia de la familia Rubiaceae. Igualmente ataca cultivos como el plátano, cítricos, guamo, guanábana y café. La infestación en los cafetales se presenta de forma agregada cuando aparecen las ninfas con la llegada de las primeras lluvias de marzo, principalmente en cafetales cercanos a bosques (Figura 9). Los saltamontes atacan en cientos de individuos que van colonizando 


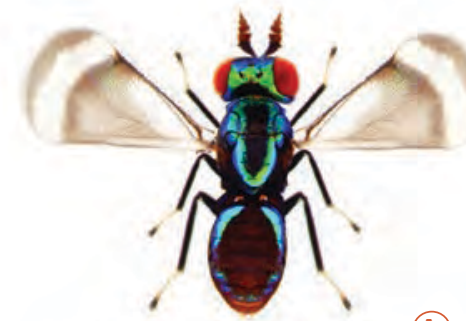

A.
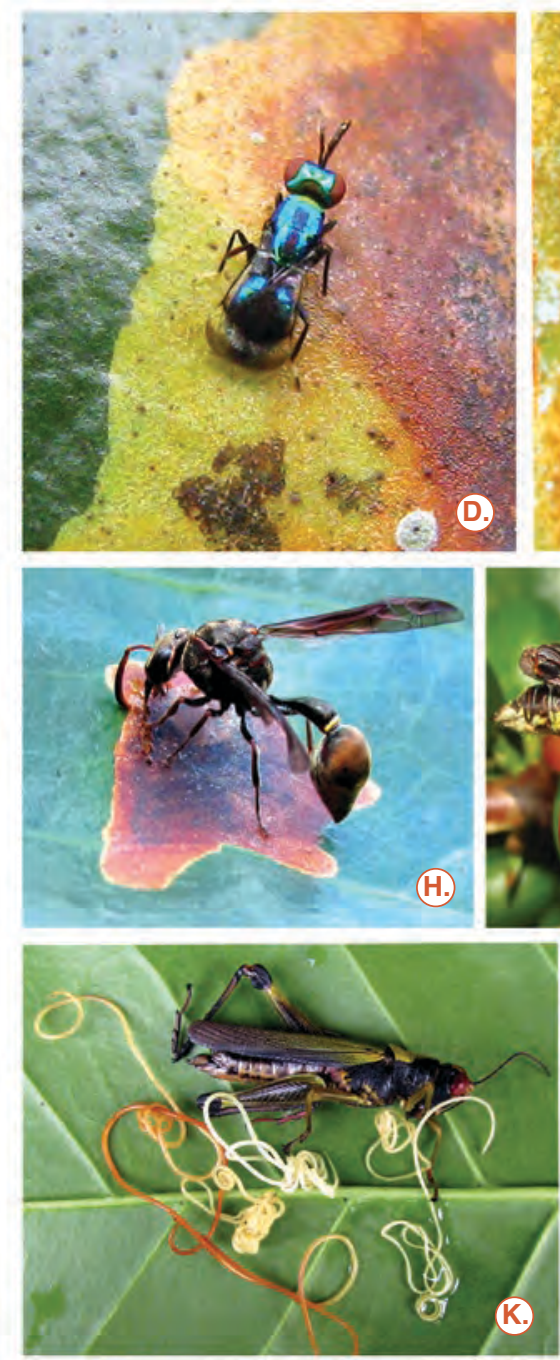

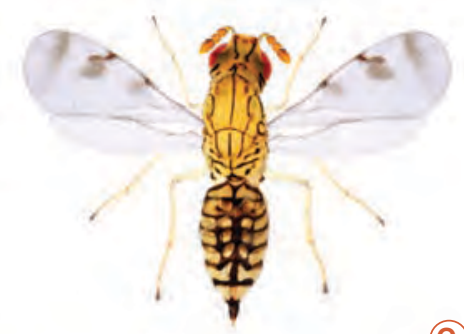

(C.)
(B.)

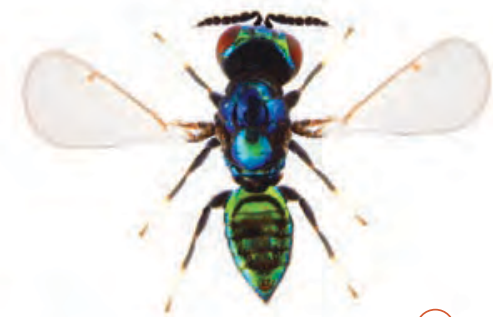

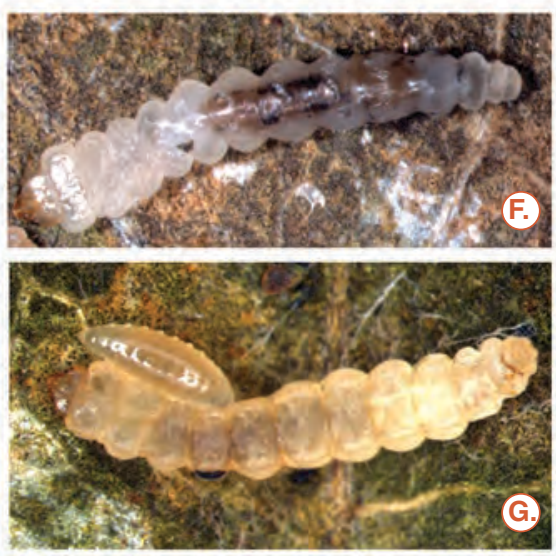
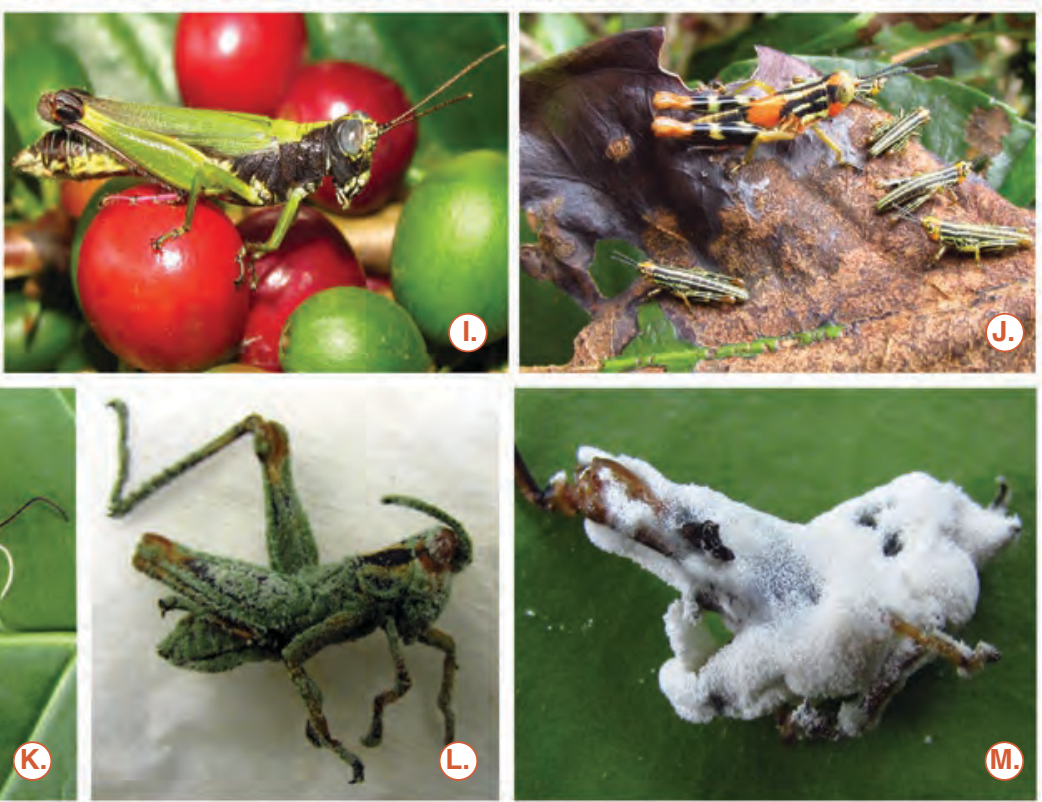

Figura 9.

Enemigos naturales del minador de la hoja del cafeto Leucoptera coffeella. A. Closterocerus coffellae. B. Closterocerus lividus. C. Zagrammosoma multilineatum. D. Closterocerus coffellae parasitando una mina de Leucoptera coffeella en café. E. Puparios de Closterocerus coffellae. F. Larva de minador parasitada por un endoparasitoide. G. Ectoparasitoide sobre larva de minador. H. Omicron sp. (Vespidae) abriendo una mina para depredar larvas de Leucoptera coffeella. I-J. Adulto y ninfas del saltamontes Poecilocloeus coffeaphilus. K. Poecilocloeus coffeaphilus parasitado por nematodos del género Mermis sp. (Mermithidae). L. Ninfa de Peocilocloeus parasitada por el hongo Metarhizium acridum. M. Ninfa de Poecilocloeus parasitada por el hongo entomopatógeno Beauveria bassiana.

El Control Natural de Insectos en el Ecosistema Cafetero Colombiano 
los árboles, con poblaciones de hasta 30-60 ninfas y 15-20 adultos por árbol, ocasionando la defoliación parcial o total de los árboles afectados (Constantino etal., 2018). Igualmente los adultos consumen la pulpa de los frutos dejando los granos expuestos, causando la caída de estos y afectando el desarrollo de los frutos de café.

En Antioquia se han hallado varios enemigos naturales del saltamontes enmascarado del café, siendo el principal el nematodo Mermis sp. (Mermithidae), que parasita al insecto (Figura 9). Estos nematodos requieren dos años para desarrollar cada generación; con las lluvias, las hembras apareadas salen del suelo y ovipositan en la vegetación. Los saltamontes consumen la vegetación contaminada con los huevos y en su tubo digestivo eclosionan los nematodos, quienes permanecen en los saltamontes de 4 a 10 semanas, y al madurar, la larva sale del hospedante matándolo y, posteriormente cae al suelo donde entran en diapausa hasta el año siguiente para parasitar una nueva generación de saltamontes.

Entre los principales depredadores se hallaron ninfas y adultos de tres especies de mantis: mantis hoja Acanthops centralis (Mantodea: Acanthopidae), Acontista cordillerae y Acontista multicolor (Mantodea: Acanthopidae) (Figura 9). Estos se observaron depredando ninfas de $P$. coffeaphilus. En cuanto a chinches asesinas, la principal especie hallada fue Zelus vespiformis (Hemiptera: Reduviidae).

Con respecto a hongos entomopatógenos, se halló en el campo una cepa de $B$. bassiana (Hypocreales: Clavicipitaceae). Esta cepa fue recolectada, aislada y depositada en el cepario de hongos entomopatógenos de Cenicafé. En pruebas de laboratorio se evaluó un aislamiento del hongo Metarhizium acridum, específico para saltamontes, logrando mortalidades del $100 \%$, al cabo de cinco días de asperjados los saltamontes, a una concentración de 1×107 conidias/mL (Constantino et al., 2018) (Figura 9).

Debido a la riqueza de enemigos naturales que presenta esta especie de saltamontes en la región, su manejo debe enfocarse al uso de insecticidas biológicos en una aproximación agroecológica, para no afectar la fauna benéfica y evitar que las poblaciones se incrementen por desequilibrios producto de la aplicación generalizada de insecticidas químicos de amplio espectro.

\section{Parasitoides y depredadores de la mosca blanca lanuda Aleurothrixus floccosus (Hemiptera: Aleyrodidae)}

A. floccosus es una especie que prevalece en períodos secos. Durante las lluvias las poblaciones disminuyen, ya que los adultos son insectos frágiles y son lavados de la vegetación. Es plaga importante de los cítricos, pero también se ha reportado en cultivos como el aguacate y el café. Su presencia en cultivos de café es ocasional y los ataques siempre han estado relacionados con la aplicación de insecticidas de amplio espectro de acción, tipo piretroides, para el control de otras plagas en cultivos asociados como el aguacate, lulo y granadilla. Los adultos son insectos voladores, tienen el cuerpo y las alas membranosas recubiertas de cera blanca. Miden 1,5 mm y se parecen a polillas diminutas. Los adultos se alimentan de la savia en el envés de las hojas tiernas. Los puntos de alimentación que hacen las ninfas y adultos causan manchas cloróticas en las hojas. Debido a su comportamiento alimenticio de succionar la savia y las características de su aparato digestivo, son insectos que en el estado de ninfas excretan importantes volúmenes de mielecilla que expulsan por el ano, el cual se deposita sobre las hojas del cafeto, lo cual favorece el desarrollo del hongo Capnodium sp., que causa la fumagina, la cual se observa sobre las hojas como una cubierta negra. Esto ocasiona una reducción en la capacidad fotosintética, producto del crecimiento del hongo, la mielecilla y abundante lanosidad.

En Colombia, A. floccosus posee una cantidad de enemigos naturales tales como avispitas parasitoides de la familia Aphelinidae: Encarsia citrella, E. aleurothrixi, E. luteola, E. basicinta, una de la familia Signiphoridae: 
Signiphora aleyrodis y una especie de la familia Platygasteridae: Amitus spiniferus. Igualmente, los huevos y ninfas de la mosca blanca lanuda son depredados por los coccinélidos Azya orbigera, C. sanguinea, Coccinella septempunctata (Coleoptera: Coccinelidae) y por larvas de crisopa Chrysoperla sp. (Neuroptera: Chrysoperlidae) (Figura 10). Los hongos entomopatógenos Aschersonia aleyrodis y Lecanicillium lecanii son importantes controladores naturales de las poblaciones de mosca blanca lanuda. Debido a que $A$. floccosus presenta varios enemigos naturales que regulan naturalmente las poblaciones de mosca blanca, se recomienda la aplicación de un producto biológico selectivo a la fauna benéfica como el hongo entomopatógeno $L$. lecanii, que es específico para mosca blanca, en una concentración de $1 \times 10^{9}$ conidias/L de agua en el envés de las hojas afectadas con presencia de adultos y ninfas.

\section{Parasitoides de la cochinilla de la raíz Puto barberi (Hemiptera: Coccoidea: Putoidae)}

Puto barberi es la especie de cochinilla más abundante en los cafetales de Colombia. Presente en la raíz principal en plantas en almácigo y levante. Son insectos de hábito chupador y se alimentan de la savia de las raíces. Son pequeñas, de forma ovalada o redondeada, generalmente cubiertas por una capa cerosa blanca en la superficie dorsal y su cuerpo es de consistencia blanda y tamaño de 3 a $10 \mathrm{~mm}$. Presenta setas cerosas caudales largas en la periferia. Las cochinillas presentan una relación mutualista (trofobiosis) con varias especies de hormigas, en la cual ambas se benefician. En este caso las hormigas se alimentan de la excreción azucarada o miel de rocío producida por las cochinillas y en contraprestación las cochinillas son protegidas por las hormigas del ataque de parasitoides y depredadores. Adicionalmente les ayudan a dispersarse. Es la especie más común en café y ataca en forma aleatoria. Se encuentra asociada en las raíces de muchas arvenses como escoba dura Sida rhombifolia (Malvaceae), papunga
Bidens pilosa (Asteraceae) y venadillo Erigeron bonariensis (Asteraceae).

Entre los enemigos naturales más importantes reportados en Colombia están dos especies de avispas de la familia Encyrtidae pertenecientes a los géneros Aenasius sp. y Hambletonia sp. (Gil et al., 2016). Todas las especies del género Aenasius y Hambletonia son endoparasitoides solitarios de insectos de la familia Pseudococcidae (Noyes, 1995). Los estados adultos de estas dos especies de parasitoides se alimentan del néctar de las flores y secreciones azucaradas de algunas arvenses, por consiguiente el manejo selectivo de arvenses nobles en las calles del cafetal y los bordes del cultivo son importantes para mantener coberturas de plantas nectaríferas y melíferas que sirven de albergue y sustrato alimenticio a la fauna benéfica (Benavides et al., 2013).

\section{Parasitoides y depredadores de la arañita roja del café Oligonychus yothersi (Acari: Tetranychidae)}

Oligonychus yothersi es un ácaro de hábitos polífagos. Las ninfas y adultos chupan el contenido de la savia de las células de las hojas desecándolas y causando manchas en los sitios de alimentación, que se manifiestan luego en una coloración bronceada característica en la haz de las hojas afectadas (Cenicafé, 2011).

La arañita roja del café es una especie estacional que se presenta en períodos prolongados de sequía y altas temperaturas. Cuando las épocas de lluvias llegan se reducen las poblaciones. Generalmente, las infestaciones comienzan en lotes de café cercanos a carreteras o caminos destapados, ocasionando que el polvo se deposite sobre las hojas. Igualmente se tiene documentado el efecto de la deposición de ceniza volcánica sobre el follaje de café, la cual tiene una acción favorable para ciertas plagas como la arañita roja O. yothersi (Gil et al., 2013), mientras que para otros insectos, depredadores y parasitoides, la ceniza ejerce un control 

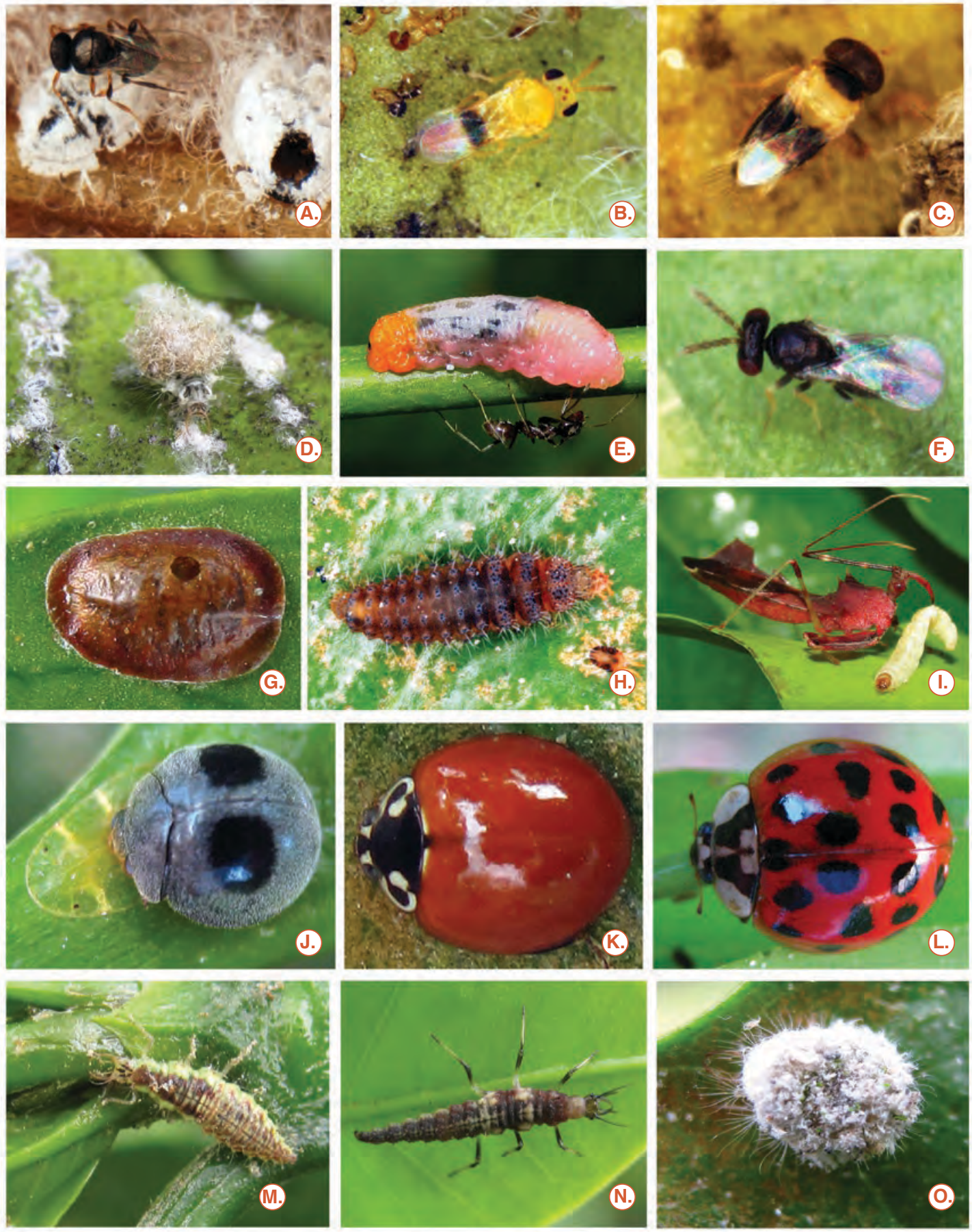

Figura 10.

Parasitoides de pupas de la mosca blanca lanuda Aleurothrixus floccosus. A. Amitus spiniferus (Platygastridae)

B. Encarsia hispida (Aphelinidae) C. Signiphora aleyrodis (Signiphoridae). D. Larva de Chrysoperla sp. depredando ninfas de mosca blanca. E. larva de Ocyptamus giganteus (Syrphidae). F-G. Aprostocetus sp (Eulophidae) parasitoide de la escama verde. H. Larva de Stethorus sp. depredando arañita roja Oligonychus yothersi. I. Socius sp. (Reduviidae) depredador generalista. J. Azya orbigera (Coccinelidae) depredando escama verde Coccus viridis. K. Cycloneda sanguinea. L. Harmonia axyridis. M-O. Larvas de Chrysoperla depredadores de arañita roja 
físico al actuar como abrasivo, eliminando la fauna benéfica. En el caso de la arañita roja, el hábito de producir un tejido sedoso sobre la haz de las hojas, las partículas de polvo y ceniza que quedan atrapadas en la cubierta de seda, le ofrecen protección y refugio contra los depredadores.

En Colombia, las poblaciones de arañita roja son reguladas naturalmente por varias especies de depredadores, siendo Stethorus sp. (Coleoptera: Coccinellidae) el enemigo natural más abundante. Este coleóptero negro y de tamaño pequeño, de 1,0 a 1,3 mm de longitud, se observa consumiendo todos los estados biológicos (huevos, larvas, ninfas y adultos) de $O$. yothersi, y es frecuente encontrar en una hoja de café hasta cinco estados entre larvas y adultos de este depredador (Figura 10).

En los cafetales también se han registrado otras especies de depredadores generalistas de arañita roja de la familia Coccinelidae como A. orbigera, C. sanguinea, Harmonia axyridis, Scymnus sp., Psyllobora confluens y Brachiacantha bistripustulata (Coleoptera: Coccinelidae). Elácaro depredador Phytoseiulus sp. (Acari: Phytoseiidae) también se observó depredando todos los estados de arañita roja. Este ácaro de color amarillo translúcido se refugia en las domacias de las hojas de café, que son cavidades que se encuentran a lo largo de la nervadura central en el envés de las hojas. Igualmente las larvas y adultos de Chrysoperla sp. (Neuroptera: Chrysopidae) (Figura 10) se observaron ejerciendo control natural sobre las poblaciones de este ácaro y otros insectos depredadores de la familia Staphylinidae (Oligota sp.) y varias especies de Diptera (Syrphidae) (Gil et al., 2013).

\section{Parasitoides y depredadores del gusano cogollero del maíz Spodoptera frugiperda (Lepidoptera: Noctuidae)}

Es una especie de lepidóptero de amplia distribución en Suramérica y Centroamérica, donde se tiene reportada como una plaga de diversos cultivos, por sus hábitos polífagos y voracidad. S. frugiperda tiene más de 62 especies de plantas hospedantes, principalmente gramíneas y cultivos como maíz, arroz, sorgo, trigo, avena, caña de azúcar, maní, ajonjolí, café, soya, tabaco, alfalfa, papa, berenjena y plantas hortícolas. Las larvas actúan como "trozadores" o "tierreros" en los cultivos; durante el día permanecen ocultas bajo el suelo, enroscados en forma de "C", cerca de las plantas que atacan, y durante la noche trozan las plántulas. En almácigos de café las larvas trozan las plántulas cerca al cuello de la raíz y consumen las hojas cotiledonales. En resiembras de café pueden observarse árboles descortezados, parcial o totalmente, más arriba del cuello de la raíz. El descortezado total que se asemeja a un anillado, ocasiona la interrupción del flujo de savia y la planta se marchita.

Para no afectar la fauna benéfica, el mejor método de control del gusano trozador es mediante el uso de cebos tóxicos preparados a base de afrecho o salvado de trigo impregnado con melaza y un insecticida de contacto. Estos cebos se preparan mezclando $1 \mathrm{~L}$ de un insecticida químico con $4 \mathrm{~L}$ de agua, $1 \mathrm{~L}$ de melaza y $15 \mathrm{~kg}$ de salvado. Igualmente, el uso de la bacteria Bacillus thuringiensis, aplicado en el cuello de la raíz y el tallo, son una opción de control biológico eficaz. Entre los enemigos naturales hallados en Colombia se encuentran:

Parasitoides de huevos: Telenomus remus (Hymenoptera: Scelionidae), Trichogramma atopovirilia (Hymenoptera: Trichogrammatidae), Chelonus insularis (Hymenoptera: Braconidae), Parasitoides de larvas: Euplectrus plathypenae (Hymenoptera: Eulophidae), Cotesia marginiventris, Meteorus laphygmae (Hymenoptera: Braconidae), Eiphosoma vitticole (Hymenoptera: Ichneumonidae), Sarcophaga sp., Sarcodexia sternodontis (Diptera: Sarcophagidae), Archytas analis, Archytas marmoratus, Gonia crassicornis, Lespesiasp., Voriasp., Winthemia quadripustulata sp. (Diptera: Tachinidae) y parasitoides de adultos: Noctuidonema guyanense (Nematoda: Acugutturidae) (Figura 11) (Cave, 1993; CABI, 2018). 


\section{Parasitoides y depredadores del gusano trozador de los almácigos de café Spodoptera latifascia (Lepidoptera: Noctuidae)}

En la zona cafetera se le conoce con el nombre vulgar de gusano tierrero o trozador del café, que aplica generalmente para la especie Spodoptera frugiperda, con la cual se le suele confundir; sin embargo, el reporte de Spodoptera latifascia atacando café es un nuevo registro de hospedante. El patrón de manchas negras dorsales en forma de media luna que presenta la larva es un carácter diagnóstico de la especie (Figura 11). S. latifascia presenta una distribución amplia desde Norte América hasta Suramérica, en un rango altitudinal entre 1.000 a 2.000 m. S. latifascia es una especie de hábitos polífagos, que se alimenta de una gran variedad de plantas de diferentes familias, entre las que se reportan el tomate Lycopersicon esculentum, papa Solanum tuberosum (Solanaceae), lechuga común Lactuca sativa (Asteraceae), maíz Zea mays (Poaceae), algodón Gossypium hirsutum (Malvaceae) (Pogue, 2002), pimentón Capsicum annuum (Solanaceae), cebolla Allium cepa (Amaryllidacae), cítricos Citrus sp., (Rutaceae), acelga Beta vulgaris var. cicla, (Amaranthaceae), girasol Helianthus annuus (Asteraceae), alfalfa Medicago sativa (Fabaceae) (Robinson et al., 2010), apio Apium graveolens (Apiaceae), berenjena Solanum melongena (Solanaceae). También ha sido reportada en plantas ornamentales como el Plumbago y Schefflera (Robinson et al., 2010). En café Coffea arabica(Rubiaceae) es un nuevo registro. Los adultos son de hábitos nocturnos, las hembras ovipositan en el envés de las hojas, en grupos de 200-300 huevos de forma gregaria. Es una especie estacional, que aparece con la llegada de las lluvias de abril y octubre en la zona central cafetera. Las larvas actúan como trozadores, permanecen ocultas en la base de los tallos de las plantas huésped y salen en la noche para alimentarse y trozar las plantas.
El daño ocasionado por las larvas de $S$. latifascia en follaje de café se manifiesta por cortes irregulares que hacen las larvas con sus mandíbulas, desde el margen de las hojas hacia el centro de la nervadura central. En plantas completamente defoliadas solo se observó la nervadura central intacta sin la lámina foliar. Se han registradoo algunas plantas con el cogollo apical del tallo central trozado; este corte causa retraso en el desarrollo de las plantas afectadas. S. latifascia no causa anillamiento o descortezamiento de tallos, ya que no se han encontrado plantas con estos síntomas en lotes afectados con esta especie de gusano tierrero. En Sevilla, Valle, en un lote de café en levante de 5.340 plantas, el porcentaje de daño de $S$. latifascia fue del $75,4 \%$, a partir del número de plantas revisadas que presentaron daño fresco en el follaje (Constantino \& Benavides, 2015).

Enemigos naturales que controlan las poblaciones de S. latifascia:

- Parasitoides de huevos: Trichogramma pretiosum (Hymenoptera:

Trichogrammatidae); T. remus (Hymenoptera: Scelionidae).

- Parasitoides de huevosy larvas: C. insularis, Chelonus curvimaculatus (Hymenoptera: Braconidae).

- Parasitoides de larvas: Sarcodexia sternodontis, Sarcophaga sp. (Diptera: Sarcophagidae); Winthemia rufiventris, W. rufopicta, Archytas incertus, Gonia sp., Voria ruralis (Diptera: Tachinidae); E. comstockii, E. platyhipenae (Hymenoptera: Eulophidae); Apanteles marginiventris sp., Meteorus laphygmae (Hymeoptera: Braconidae); Eiphosoma vitticolle (Hymneoptera: Ichneumonidae); Microcharops sp. (Hymenoptera: Chalcidae).

- Parasitoides de larvas y pupas: Archytas marmoratus (Diptera: Tachinidae).

- Parasitoides de pupas: Brachymeria ovata (Hymenoptera: Chalcidae). 
- Depredadores de huevos y larvas: C. sanguinea, Coleomegilla maculata (Coleoptera: Coccinelidae); Orius insidiosus (Hemiptera: Anthocoridae); Podisus maculiventris, P. connexivus (Hemiptera: Pentatomidae); Solenopsis invicta (Hymenoptera: Formicidae); Polistes erytrocephalus., Polybia sp, Parachartergus apicalis (Hymenoptera: Vespidae).

- Entomopatógenos: virus: Baculovirus spodoptera (Caudovirales: Baculoviridae); bacterias: $B$. thuringiensis (Bacillales: Bacillaceae); hongos: B. bassiana (Hypocreales: Cordycipitaceae); $M$. anisopliae (Hypocreales: Clavicipitaceae); nematodos: Steinernema feltiae, S. carpocapsae (Rhabditida: Steinernematidae) (Van Lenteren \& Bueno, 2003; Holloway et al., 1987; King \& Saunders, 1984; Pogue, 2002).

\section{Parasitoides y depredadores de la polilla de cuatro ventanas Rotschildia oryzaba cauca (Lepidoptera: Saturnidae)}

Rotschildia orizaba (Westwood, 1853) es una polilla nocturna grande y vistosa, con una envergadura alar de $12 \mathrm{~cm}$. Se distribuye desde México hasta Bolivia. Está representada por seis subspecies, de las cuales $R$. orizaba cauca Rothschild, 1907, está restringida en las cordilleras Central y Occidental de Colombia, en los departamentos de Antioquia, Caldas, Risaralda, Quindío, Valle y Cauca y $R$. orizaba equatorialis Rotschild, 1907, en el Sur de Colombia (Nariño) y Ecuador.

$R$. orizaba es una especie de hábitos polífagos. Sus plantas hospedantes incluyen árboles y arbustos como el estoraque Liquidambar sp. (Altingiaceae), ligustro Ligustrum sp. (Oleaceae), ciruela Prunus sp. (Rosaceae), jobo Spondias mombin (Anacardiaceae), cítricos Citrus sp. (Rutaceae), pomarroso Eugenia jambos (Myrtaceae), cámbulo rojo Erythrina americana (Fabaceae) y en café Coffea arabica (Rubiaceae)
(Quezada \& Rodríguez, 1989; Cárdenas \& Posada, 2001). En café se considera una especie ocasional, que aparece debido a desequilibrios causados por la aplicación de plaguicidas que eliminan sus enemigos naturales. Los adultos son de hábitos nocturnos, se observan los vuelos al inicio del período de lluvias. El daño lo ocasiona la larva sobre el follaje. Cuando las poblaciones son altas pueden defoliar completamente un árbol de café.

R. orizaba presenta buen control natural por diferentes especies de avispas y moscas parasitoides (Figura 11). En la etapa de huevo se han registrado especies de avispas del género Trichogramma (Hymenoptera: Trichogrammatidae), Anastatus (Hymenoptera: Eulophidae) y Telenomus (Hymenoptera: Scelionidae). Del estado de pupa Brachymeria, Conura (Hymenoptera: Chalcidae) y Belvosia (Diptera: Tachinidae) (Quezada \& Rodríguez, 1989; Cárdenas \& Posada, 2001). En el campo se observó al parasitoide de larvas y pupas Brachymeria sp. sobre una larva de Eacles imperialis que había sido infectada con $B$. thuringiensis. En este caso se corrobora el efecto inocuo que tiene $B$. thuringiensis en la fauna benéfica, ya que es específico para larvas de lepidópteros. Las especies de parasitoides más importantes de R. orizaba son Belvosia nigrifrons y Lespesia sp. (Diptera: Tachinidae). De acuerdo con Quezada \& Rodríguez (1989), las poblaciones de $R$. orizaba se encuentran en equilibrio cuando existe un $70 \%$ de parasitismo, que unido con otros factores de mortalidad, solo permiten la emergencia de un $10 \%$ de las mariposas de sus capullos.

Con respecto a entomopatógenos, las larvas de Rotschildia en el campo son susceptibles a la bacteria $B$. thuringiensis (Bt). En septiembre de 2013, en un lote de café afectado por $R$. orizaba en una finca cafetera de Armenia, Quindío, se confirmó el efecto patogénico de la bacteria Bt sobre las larvas de Rotschildia, después de asperjado el bioinsecticida sobre las larvas. Este insecticida microbial está elaborado a base de una cepa patogénica (L-BT/K) de la bacteria B. thuringiensis var. Kurstaki, serotipos 3a y 3b, específico para el control de larvas de lepidópteros. 

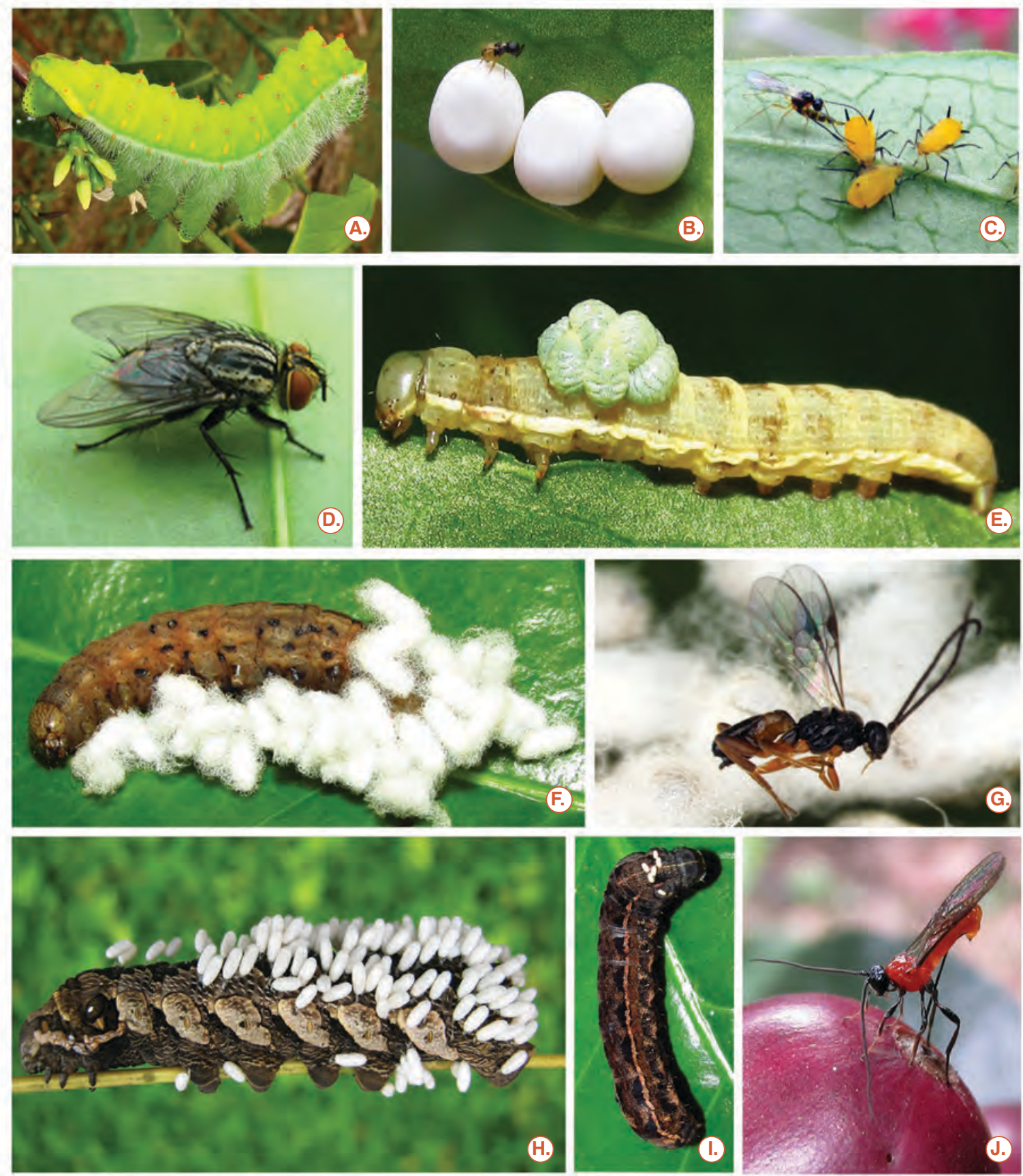

Figura 11.

A. Larva de Rothschildia oryzaba en café. B. Trichogramma sp. parasitando huevos de Rothschildia oryzaba.

C. Lysiphlebus testaceipes (Braconidae) parasitando Aphis nerii. D. Lespesia sp. (Tachinidae) parasitoide de larvas y pupas de Rotschildia oryzaba. E. Larvas de ectoparasitoide gregario Euplectrus plathypenae (Eulophidae) sobre larva de Spodoptera frugiperda. F-G. Cotesia marginiventris (Braconidae) parasitoide de larvas de Spodoptera frugiperda. H. larva de Sphingidae parastidad por Cotesia glomerata (Braconidae). I. Larva de Spodoptera latifascia parasitada por Winthemia rufiventris (Tachinidae) con posturas sobre el dorso detrás de la cabeza. J. Doryctobracon (Braconidae) parasitando larvas de mosca de la fruta Anastrepha fraterculus en fruto de café. 
Los efectos de control de larvas de $R$. orizaba que se observaron en los cafetales fueron la disminución del daño fresco, del número promedio de larvas por árbol, deformación y cambio de color de las larvas de un tono verde a negro y pérdida de movilidad. Igualmente, se observaron larvas muertas con consistencia flácida, secas y adheridas de las patas anales que se encontraban descolgadas de las ramas de los árboles de café.

El Btademás presenta un control selectivo, que permite la recuperación de la fauna benéfica, la cual ejerce su acción complementaria sobre poblaciones remanentes de la plaga, logrando un verdadero programa de control integrado eficiente y económico.

\section{Parasitoides y depredadores del gusano biringo Agrotis ipsilon (Lepidoptera: Noctuidae)}

Agrotis ipsilon es una especie de distribución cosmopolita y particularmente en la región Andina en Suramérica, donde es considerada plaga de varios cultivos (Quimbayo et al., 2010). Tiene un amplio número de plantas hospedantes, tanto cultivadas como silvestres.

En Colombia los cultivos más afectados son maíz, sorgo, arroz, algodón, fríjol, tabaco, ajonjolí, maní, papa, tomate, cebolla, repollo, zanahoria, girasol, soya, fresa y varias plantas ornamentales y malezas, principalmente gramíneas, bledo Amaranthus dubius y paico Chenopodium anthelminticum (Vélez, 1997). Tienen mayor preferencia por las arvenses y los cultivos son atacados cuando éstas han sido consumidas o eliminadas con herbicidas.

El principal daño en café se presenta en siembras nuevas de menos de ocho meses de edad, en lotes donde antes hubo cultivos de maíz o pastos de forraje para ganado. El daño lo ocasiona la larva con sus mandíbulas cuando muerde y roe los tallos de café, causando un anillado parcial o total de la corteza, el cual puede darse en el cuello de la raíz principal a unos $5 \mathrm{~cm}$ de profundidad, cuando las larvas están pequeñas y hasta 8 cm por encima del cuello de la raíz, cuando la larva está en quinto estadio de desarrollo. El anillado es de forma irregular y con los bordes de las lesiones roídos, lesiones que pueden confundirse con el anillado causado por babosas, pero en estas el anillado es parejo con cortes regulares. También se asemejan al daño causado por el gusano trozador y descortezador del tallo de café $S$. frugiperda, pero en esta especie los bordes de los cortes sobre la corteza del tallo son de forma aserrada (Constantino et al., 2013). Cuando el anillado de la corteza del tallo es total, se interrumpe el flujo de savia y la planta afectada se marchita. A. ipsilon presenta muchos enemigos naturales específicos, que se usan para el control de sus poblaciones. Entre los más importantes están los parasitoides de huevos como $T$. pretiosum (Hymenoptera: Trichogrammatidae) y Telenomus sp. (Scelionidae). Las larvas son parasitadas por moscas de la familia Tachinidae tales como Linnaemya compta, Gonia lineata, Eucelatoria heliothis y Architas cirphis; así como por las avispas $C$. marginiventris, Apanteles sp., Meteorus sp. (Hymenoptera: Braconidae), Ophion flavidus (Hymenoptera: Ichneumonidae) y Spilochalcis femorata (Hymenoptera: Chalcidae). En cuanto a depredadores, las larvas son depredadas por avispas del género Polistes sp. (Hymenoptera: Vespidae) y chinches de los géneros Zelus sp. (Hemiptera: Reduviidae) y Podisus sp. (Hemiptera: Pentatomidae) (Vélez, 1997; Coto \& Saunders, 2004). El uso de formulaciones comerciales de la bacteria $B$. thuringiensis, aplicado en horas de la tarde, es efectivo para el control de larvas, ya que este agente entomopatógeno es específico para larvas de lepidópteros.

\section{Parasitoides y depredadores del falso gusano biringo Feltia subterranea (Lepidoptera: Noctuidae)}

Feltia subterranea se distribuye desde el Sur de Estados Unidos, todo Centro América y Suramérica donde es considerada plaga de varios cultivos (Quimbayo et al., 2010; Coto \& 
Saunders, 2004). Tiene un amplio número de plantas hospedantes, tanto cultivadas como silvestres (cacao, café, caña de azúcar, maíz, pastos).

La apariencia de las larvas es similar a la de Agrotis ipsilon, pero de contextura robusta y piel corácea, gris oscuro y cabeza negra. Las larvas se alimentan de noche, en el día permanecen enterradas en el suelo hasta una profundidad de $20 \mathrm{~cm}$, o debajo de materia orgánica en descomposición o residuos de cosecha. Las larvas salen en la noche y se alimentan de follaje en plántulas en levante cuando están pequeñas. Las larvas grandes trozan los tallos cerca de la superficie del suelo. En plántulas de café en levante, de menos de ocho meses, anillan los tallos causando el marchitamiento de las plántulas. Se enrollan cuando las molestan. Pueden subsistir hasta un mes en residuos de cosechas y socas de maíz.

Los principales enemigos de Feltia subterranea reportados son:

- Parasitoides de larvas: Apanteles griffini, C. insularis, Meteorus laeventris, Meteorus laphygmae, Microgasterfeltiae (Hymenoptera: Braconidae), Lespesia archippivora (Riley), Arcoglossa vetula Rinhard, Linnaemya comta (Fallen), Linnaemya sp., Zenilla blanda (Diptera: Tachinidae).

- Parasitoides de larvas y pupas: Eniscopilus sp., Ichneumon sp., Netelia semirufa (Hymenoptera: Ichneumonidae) (Coto \& Saunders, 2004).
- Depredadores de larvas: Podisus sp. (Hemiptera: Pentatomidae); Polistes erytrocephalus., Polybia sp, Parachartergus apicalis (Hymenoptera: Vespidae) (Figura 11).

\section{Parasitoides y depredadores delfalsomedidorChrysodeixis includens (Lepidoptera: Noctuidae)}

Incluido anteriormente en el género Pseudoplusia y luego transferido al género Chrysodeixis. El falso medidor es una especie ampliamente distribuida desde el Sur de Estados Unidos, todo Centro América y Suramérica. La larva se alimenta del follaje de varios cultivos como girasol Helianthus annus L., soya Glycine max (L.), alfalfa Medicago sativa L., algodón Gossypium hirsutum L., fríjol Phaselous vulgaris L., linaza Linum usitatissimum L., tabaco Nicotiana tabacum L. y café Coffea arabica (Artigas, 1994). Las larvas se alimentan sobre el follaje de café, causando perforaciones pequeñas y luego en la medida que las larvas crecen dejan solo la nervadura central. El principal parasitoide primario es $C$. truncatellum (Hymenoptera: Encyrtidae) (Cárdenas \& Posada, 2001). Esta especie de parasitoide presenta parasitismo poliembriónico, condición en la que el huevo depositado en el huésped se divide asexualmente produciendo multitud de nuevos individuos (Figura 7).

En la Tabla 2 se presenta el listado de algunos enemigos naturales de plagas del cultivo de café en Colombia. 
Tabla 2. Especies de enemigos naturales de artrópodos fitófagos del cultivo del café en Colombia. Convenciones: $(\mathrm{H}$ : huevos, N: ninfas, L: larvas, P: pupas, A: adultos).

\begin{tabular}{|c|c|c|c|}
\hline $\begin{array}{l}\text { Plaga huésped } \\
\text { principal/ } \\
\text { potencial }\end{array}$ & Enemigo natural & Orden/Familia & Hábitos \\
\hline \multirow{32}{*}{$\begin{array}{c}\text { Broca del café } \\
\text { Hypothenemus } \\
\text { hampei }\end{array}$} & Phymastichus coffea & Hymenoptera: Eulophidae & Endoparasitoide A \\
\hline & Prorops nasuta & Hymenoptera: Bethylidae & Ectoparasitoide L \\
\hline & Cephalonomia stephanoderis & Hymenoptera: Bethylidae & Ectoparasitoide L \\
\hline & Cryptoxilos sp. & Hymenoptera: Braconidae & Endoparasitoide L \\
\hline & Cathartus quadricollis & Coleoptera: Silvanidae & Depredador H, L, P, A \\
\hline & Ahasverus advena & Coleoptera: Silvanidae & Depredador H,L,P,A \\
\hline & Monanus sp. & Coleoptera: Silvanidae & Depredador H,L,P \\
\hline & Europs sp. & Coleoptera: Silvanidae & Depredador H,L,P \\
\hline & Xylocoris sp. & Hemiptera: Anthocoridae & Depredador H,L,P \\
\hline & Calliodes sp. & Hemiptera: Anthocoridae & Depredador H,L,P \\
\hline & Scoloposcelis sp. & Hemiptera: Anthocoridae & Depredador H,L,P \\
\hline & Solenopsis picea & Hymenoptera: Formicidae & Depredador H,L,P \\
\hline & Crematogaster crinosa & Hymenoptera: Formicidae & Depredador L,A \\
\hline & Cremtaogaster curvispinosa & Hymenoptera: Formicidae & Depredador L,A \\
\hline & Tapinoma melanocephalum & Hymenoptera: Formicidae & Depredador H,L,P \\
\hline & Pheidole sp. & Hymenoptera: Formicidae & Depredador A \\
\hline & Brachymyrmex sp. & Hymenoptera: Formicidae & Depredador L,A \\
\hline & Pseudomyrmex sp. & Hymenoptera: Formicidae & Depredador H,L,P,A \\
\hline & Mycocepurus sp. & Hymenoptera: Formicidae & Depredador H,L,P,A \\
\hline & Dorymirmex sp. & Hymenoptera: Formicidae & Depredador H,L,P,A \\
\hline & Prenolepis sp. & Hymenoptera: Formicidae & Depredador H,L,P,A \\
\hline & Wasmannia sp. & Hymenoptera: Formicidae & Depredador H,L,P \\
\hline & Azteca sp. & Hymenoptera: Formicidae & Depredador A \\
\hline & Steinernema colombiense & Nematoda: Steinernematidae & Parasitos L,P,A \\
\hline & Steinernema feltiae & Nematoda: Steinernematidae & Parasitos L,P,A \\
\hline & Steinernema carpocapsae & Nematoda: Steinernematidae & Parasitos L,P,A \\
\hline & Heterorhabditis bacteriophora & Nematoda: Steinernematidae & Parasitos L,P,A \\
\hline & Beavueria bassiana & Hypocreales:Cordycipitaceae & Entomopatógeno L,P,A \\
\hline & Metarhizium anisopliae & Hypocreales: Clavicipitaceae & Entomopatógeno L,P,A \\
\hline & Fusarium oxysporum & Hypocreales: Nectriaceae & Entomopatógeno A \\
\hline & Paecilomyces lilacinus & Hypocreales: Ophiocordycipitaceae & Entomopatógeno A \\
\hline & Hirsutella eleutheratorum & Hypocreales: Ophiocordycipitaceae & Entomopatógeno A \\
\hline
\end{tabular}

Continúa... 


\begin{tabular}{|c|c|c|c|}
\hline $\begin{array}{c}\text { Plaga huésped } \\
\text { principal } \\
\text { potencial }\end{array}$ & Enemigo natural & Orden/Familia & Hábitos \\
\hline \multirow{16}{*}{$\begin{array}{c}\text { Minador de la } \\
\text { hoja del café } \\
\text { Leucoptera } \\
\text { coffeella }\end{array}$} & Closterocerus coffeellae & Hymenoptera: Eulophidae & Endoparasitoide L \\
\hline & Closterocerus lividus & Hymenoptera: Eulophidae & Endoparasitoide L \\
\hline & Zagrammosoma multilineatum & Hymenoptera: Eulophidae & Ectoparasitoide L \\
\hline & Pnigalio sarasolai & Hymenoptera: Eulophidae & Ectoparasitoide L \\
\hline & Horismenus cupreus & Hymenoptera: Eulophidae & Ectoparasitoide L,P \\
\hline & Horismenus sp. nov. & Hymenoptera: Eulophidae & Ectoparasitoide L,P \\
\hline & Proacrias coffeae & Hymenoptera: Eulophidae & Hiperparasitoide L \\
\hline & Apleurotropis sp. & Hymenoptera: Eulophidae & Ectoparasitoide L \\
\hline & Chrysocharis livida & Hymenoptera: Eulophidae & Endoparasitoide L \\
\hline & Achrysocharoides sp. & Hymenoptera: Eulophidae & Endoparasitoide L \\
\hline & Allobracon primus & Hymenoptera: Eulophidae & Endoparasitoide L \\
\hline & Polistes versicolor & Hymenoptera:Vespidae & Depredador L \\
\hline & Polistes carnifex & Hymenoptera:Vespidae & Depredador L \\
\hline & Polistes erytrocephalus & Hymenoptera:Vespidae & Depredador L \\
\hline & Polybia sp. & Hymenoptera:Vespidae & Depredador L \\
\hline & Omicron sp. & Hymenoptera:Vespidae & Depredador L \\
\hline \multirow{11}{*}{$\begin{array}{c}\text { Cochinilla de las } \\
\text { ramas } \\
\text { Planococcus citri }\end{array}$} & Stethorus sp. & Coleoptera: Coccinelidae & Depredador H,N,L,A \\
\hline & Cycloneda sanguinea & Coleoptera: Coccinelidae & Depredador H,N,L,A \\
\hline & Harmonia axyridis & Coleoptera: Coccinelidae & Depredador $\mathrm{H}, \mathrm{N}, \mathrm{L}, \mathrm{A}$ \\
\hline & Psyllobora confluens & Coleoptera: Coccinelidae & Depredador H,N,L,A \\
\hline & Azya orbigera & Coleoptera: Coccinelidae & Depredador $\mathrm{H}, \mathrm{N}, \mathrm{L}, \mathrm{A}$ \\
\hline & Brachiacantha bistripustulata & Coleoptera: Coccinelidae & Depredador H,N,L,A \\
\hline & Scymnus hamatus & Coleoptera: Coccinelidae & Depredador $\mathrm{H}, \mathrm{N}, \mathrm{L}, \mathrm{A}$ \\
\hline & Oligota centralis & Coleoptera: Staphylinidae & Depredador H,N,L,A \\
\hline & Phytoseiulus sp. & Acari: Phytoseiidae & Depredador N,L,A \\
\hline & Chrysoperla sp. & Neuroptera: Chrysopidae & Depredador H,L,N,A \\
\hline & Ocyptamus giganteus & Diptera: Syrphidae & Depredador H, L, N \\
\hline \multirow{5}{*}{$\begin{array}{c}\text { Cochinilla de la } \\
\text { raíz } \\
\text { Puto barberi }\end{array}$} & Leptomastix dactylopii & Hymenoptera: Encyrtidae & Endoparasitoide N,A \\
\hline & Cryptolaemus montrouzieri & Coleoptera: Coccinelidae & Depredador H,N,A \\
\hline & Harmonia axyridis & Coleoptera: Coccinelidae & Depredador H,N,A \\
\hline & Tenuisvalvae notata & Coleoptera: Coccinelidae & Depredador H,N,A \\
\hline & Diomus sp. & Coleoptera: Coccinelidae & Depredador H,N,A \\
\hline
\end{tabular}




\begin{tabular}{|c|c|c|c|}
\hline $\begin{array}{l}\text { Plaga huésped } \\
\text { principal/ } \\
\text { potencial }\end{array}$ & Enemigo natural & Orden/Familia & Hábitos \\
\hline \multirow{13}{*}{$\begin{array}{c}\text { Escama verde del } \\
\text { café } \\
\text { Coccus viridis }\end{array}$} & Aenasius cer. a bolowi & Hymenoptera: Encyrtidae & Endoparasitoide N,A \\
\hline & Hambletonia sp. & Hymenoptera: Encyrtidae & Endoparasitoide N,A \\
\hline & Metaphycus helvolus & Hymenoptera: Encyrtidae & Endoparasitoide N \\
\hline & Metaphycus stanleyi & Hymenoptera: Encyrtidae & Endoparasitoide $\mathrm{N}$ \\
\hline & Anicetus annulatus & Hymenoptera: Encyrtidae & Endoparasitoide $\mathrm{N}$ \\
\hline & Coccophagus rusti & Hymenoptera: Aphelinidae & Endoparasitoide N \\
\hline & Marietta caridei & Hymenoptera: Aphelinidae & Endoparasitoide $\mathrm{N}$ \\
\hline & Aprostocetus sp. & Hymenoptera: Eulophidae & Endoparasitoide $\mathrm{N}$ \\
\hline & Signiphora bifasciata & Hymenoptera: Signiphoridae & Hiperparasitoide \\
\hline & Lecanicillium lecanii & Hypocreales: Clavicipitaceae & Entomopatógeno N,A \\
\hline & Aschersonia aleyrodis & Hypocreales: Clavicipitaceae & Entomopatógeno N,A \\
\hline & Azya orbigera & Coleoptera: Coccinelidae & Depredador H,N,A \\
\hline & Ocyptamus giganteus & Diptera: Syrphidae & Depredador H, N, P, A \\
\hline \multirow{3}{*}{$\begin{array}{l}\text { Escama circular } \\
\text { Saisettia coffeae }\end{array}$} & Scutellista cyanea & Hymenoptera: Pteromalidae & Endoparasitoide N,A \\
\hline & Lecaniobius sp. & Hymenoptea: Eulophidae & Endoparasitoide N,A \\
\hline & Azya orbigera & Coleoptera: Coccinelidae & Depredador H,N,A \\
\hline \multirow{3}{*}{$\begin{array}{l}\text { Escama } \\
\text { articulada } \\
\text { Selenaspidius } \\
\text { articulatus }\end{array}$} & Aspidiotiphagus citrinus & Hymenoptera: Eulophidae & Endoparasitoide N,A \\
\hline & Aphytis sp. & Hymenoptera:Eulophidae & Endoparasitoide N,A \\
\hline & Encarsia citrina & Hymenoptera: Aphelinidae & Endoparasitoide N,A \\
\hline \multirow{2}{*}{$\begin{array}{c}\text { Cochinilla cerosa } \\
\text { Ceroplastes sp. }\end{array}$} & Scutellista cyanea & Hymenoptera:Pteromalidae & Endoparasitoide N,A \\
\hline & Aschersonia aleyrodis & Hypocreales: Clavicipitaceae & Entomopatógeno N,A \\
\hline \multirow{10}{*}{$\begin{array}{l}\text { Mosca blanca } \\
\text { lanuda } \\
\text { Aleurothrixus } \\
\text { floccosus }\end{array}$} & Coccidencyrtus sp. & Hymenoptera: Encyrtidae & Endoparasitoide N,P \\
\hline & Signiphora aleyrodis & Hymenoptera: Signiphoridae & Endoparasitoide N,P \\
\hline & Signiphora townsendi & Hymenoptera: Signiphoridae & Endoparasitoide N,P \\
\hline & Eretmocerus sp. & Hymenoptera: Aphelinidae & Endoparasitoide N,P \\
\hline & Encarsia quaintancei & Hymenoptera: Aphelinidae & Endoparasitoide N,P \\
\hline & Encarsia hispida & Hymenoptera: Aphelinidae & Endoparasitoide N,P \\
\hline & Amitus spiniferus & Hymenoptera: Platygastridae & Endoparasitoide N,P \\
\hline & Delphastus pusillus & Coleoptera: Coccinelidae & Depredador H,N,P \\
\hline & Azya orbigera & Coleoptera: Coccinelidae & Depredador H,N,P \\
\hline & Chrysoperla sp. & Neuroptera: Chrysopidae & Depredador H,N,P \\
\hline \multirow{7}{*}{$\begin{array}{l}\text { Pulgón verde } \\
\text { Myzus persicae }\end{array}$} & Lysiphlebus testaceipes & Hymenoptera: Braconidae & Endoparasitoide $\mathrm{N}$ \\
\hline & Cycloneda sanguinea & Coleoptera: Coccinelidae & Depredador N, A \\
\hline & Azya orbigera & Coleoptera: Coccinelidae & Depredador N, A \\
\hline & Harmonia axyridis & Coleoptera: Coccinelidae & Depredador N, A \\
\hline & Chrysoperla sp. & Neuroptera: Chrysopidae & Depredador N, A \\
\hline & Orius tristicolor & Hemiptera: Anthocoridae & Depredador N, A \\
\hline & Allograpta argentipila & Diptera: Syrphidae & Depredador N, A \\
\hline
\end{tabular}


...continuación

\begin{tabular}{|c|c|c|c|}
\hline $\begin{array}{l}\text { Plaga huésped } \\
\text { principal/ } \\
\text { potencial }\end{array}$ & Enemigo natural & Orden/Familia & Hábitos \\
\hline \multirow{6}{*}{$\begin{array}{l}\text { Pulgón del } \\
\text { algodón } \\
\text { Aphis gossypii }\end{array}$} & Lysiphlebus testaceipes & Hymenoptera: Braconidae & Endoparasitoide $\mathrm{N}$ \\
\hline & Cycloneda sanguinea & Coleoptera: Coccinelidae & Depredador N, A \\
\hline & Harmonia axyridis & Coleoptera: Coccinelidae & Depredador N, A \\
\hline & Chrysoperla sp & Neuroptera: Chrysopidae & Depredador N, A \\
\hline & Allograpta sp. & Diptera: Syrphidae & Depredador N, A \\
\hline & Baccha bonleyi & Diptera: Syrphidae & Depredador N, A \\
\hline \multirow{4}{*}{$\begin{array}{l}\text { Pulgón negro de } \\
\text { los cítricos } \\
\text { Toxoptera aurantii }\end{array}$} & Aphidius sp. & Hymenoptera: Braconidae & Endoparasitoide N \\
\hline & Cycloneda sanguinea & Coleoptera: Coccinelidae & Depredador N, A \\
\hline & Harmonia axyridis & Coleoptera: Coccinelidae & Depredador N, A \\
\hline & Chrysoperla sp & Neuroptera: Chrysopidae & Depredador N, A \\
\hline \multirow{4}{*}{$\begin{array}{c}\text { Mosca de la fruta } \\
\text { Anastrepha } \\
\text { fraterculus }\end{array}$} & Doryctobracon crawfordi & Hym: Braconidae & Endoparasitoide L \\
\hline & Opius anastrephae & Hym: Braconidae & Endoparasitoide L \\
\hline & Utetes anastrephae & Hym: Braconidae & Endoparasitoide L \\
\hline & Odontosema anastrephae & Hym: Figitidae & Endoparasitoide L \\
\hline $\begin{array}{l}\text { Mosca de la fruta } \\
\text { Anastrepha striata }\end{array}$ & Utetes anastrephae & Hym: Braconidae & Endoparasitoide L \\
\hline \multirow{2}{*}{$\begin{array}{c}\text { Mosca del } \\
\text { Mediterráneo } \\
\text { Ceratitis capitata }\end{array}$} & Microcrasis sp. & Hym: Braconidae & Endoparasitoide L \\
\hline & Doryctobracon areolatus & Hym: Braconidae & Endoparasitoide L \\
\hline $\begin{array}{c}\text { Mosca azul de la } \\
\text { fruta } \\
\text { Neosilba sp. }\end{array}$ & Doryctobracon areolatus & Hym: Braconidae & Endoparasitoide L \\
\hline
\end{tabular}

\section{Iiteratura citada}

Altieri, M. A., \& Nicholls, C. I. (1999). Chapter 39 - Classical biological control in Latin America. past, present, and future. In T.S. Bellows \& T.W. Fisher (Eds.), Handbook of Biological Control. (pp. 975- 991). Academic Press. https://doi.org/10.1016/B978-012257305-7/50086-2

Artigas, J. N. 1994. Entomología Económica. Insectos de interés agrícola, forestal, médico y veterinario (nativos, introducidos y susceptibles de ser introducidos). Ediciones Universidad de Concepción.

Askew, R.R., \& Shaw, M.R. (1986). Parasitoid communities: their size, structure and development. In J. Waage, \& D. Greathead (Eds.), Insect Parasitoids (pp. 225-264). Academic Press.

62 
Bacca, R. T. (2011). Conozca las avispitas que hace mas de 15 años se encuentran en sus cafetales atacando la broca. Brocarta, 41, 1-2. https://www.cenicafe.org/es/publications/brc041.pdf

Bacca, T., López, J. C., \& Benavides Machado, P. (2012). Evaluación de suplementos alimentícios en adultos del parasitoide Prorops nasuta (Hymenoptera: Bethylidae). Boletín Científico Centro de Museos de Historia Natural, 16(1), 89-98.

Giraldo-Jaramillo, M., Galindo-Leva, L. A., Benavides Machado, P., \& Forero, D. (2011). Aprenda a conocer las chinches depredadoras de plagas del café. Avances Técnicos Cenicafé, 412, 1-8. http://hdl. handle.net/10778/338

Bellows, T. S. (1993). Introduction of natural enemies for suppression of arthropod pests. In R. Lumsden \& J. Vaughn (Eds.), Pest Management: Biologically Based Technologies (pp. 82-89). American Chemical Society.

Benavides Machado, P. (2008). Los parasitoides en programas de control biológico. En A. E. Bustillo Parley (Ed.), Los insectos y su manejo en la caficultura colombiana (pp. 114-125). Cenicafé.

Benavides Machado, P., Vera, L. Y.; Gil-Palacio, Z. 2008. Depredadores en el control biológico. En A. E. Bustillo Parley (Ed.), Los insectos y su manejo en la caficultura colombiana (pp. 126-132). Cenicafé.

Benavides Machado, P., Gil Palacio, Z. N., Constantino, L. M., Villegas García, C., \& Giraldo Jaramillo, M. (2013). Plagas del café. Broca, minador, cochinillas harinosas y monalonion. En Federación Nacional de Cafeteros de Colombia (Ed.), Manual del cafetero colombiano: investigación y tecnología para la sostenibilidad de la caficultura (Vol. 2, pp. 215-260). Cenicafé.

Benavides Machado, P., Gil Palacio, Z. N., Constantino, L. M., Villegas García, C., \& Giraldo Jaramillo, M. (2013). Plagas del café. Broca, minador, cochinillas harinosas y monalonion. En Federación Nacional de Cafeteros de Colombia (Ed.), Manual del cafetero colombiano: investigación y tecnología para la sostenibilidad de la caficultura (Vol. 2, pp. 215-260). Cenicafé.

Buffington, M. L., \& Polaszek, A. (2009). Recent occurrence of Aphanogmus dictynna (Waterston) (Hymenoptera:Ceraphronidae) in Kenya-animportanthyperparasitoid of the coffeeberryborer Hypothenemus hampei (Ferrari) (Coleoptera: Curculionidae). Zootaxa, 2214, 62-68. https://www.biotaxa.org/Zootaxal article/view/zootaxa.2214.1.4/0

Bustillo-Parley, A. E., Cardenas, R., Villalba, D. A., Benavides Machado, P., Orozco, J., \& Posada, F. J. (1998). Manejo integrado de la broca del café: Hypothenemus hampei (Ferrari) en Colombia. Cenicafé. http://hdl.handle.net/10778/848

Bustillo-Parley, A. E., Cárdenas, R., \& Posada, F.J. (2002). Natural enemies and competitors of Hypothenemus hampei (Ferrari) (Coleoptera:Scolytidae) in Colombia. Neotropical Entomology, 31(4), 635639. https://doi.org/10.1590/S1519-566X2002000400018

CABI. (2018). Invasive Species Compendium: Spodoptera frugiperda (Fall Armyworm) [Data set]. Retrieved May 24, 2019, from https://www.cabi.org/isc/datasheet/29810

Cárdenas, R., \& Posada, F.J. 2001. Los insectos y otros habitantes de cafetales y platanales. Cenicafé.

Carvalho, G. A., Miranda, J. C., Vilela, F. Z., Moura, A. P., \& Moraes, J. C. (2004). Impacto de inseticidas sobre vespas predadoras e parasitóides e sua eficiência no controle de Leucoptera coffeella (GuérinMèneville \& Perrottet, 1842) (Lepidoptera: Lyonetiidae). Arquivos do Instituto Biológico, 71(1), 63-70. http:/l www.sbicafe.ufv.br/handle/123456789/1435

Cave, R. (1993). Parasitoides larvales y rurales de Spodoptera frugiperda(Smith) (Lepidoptera: Noctuidae) en Centro America con una clave para las especies encontradas en Honduras. Ceiba, 34(1), 33-56. 
Centro Nacional de Investigaciones de Cáfe. (2013). Informe anual Cenicafé 2013. https://www.cenicafe. org/es/publications/InformeAnual 2013.pdf

Clausen, C. P. (1962). Entomophagous Insects. McGraw-Hill Co.

Constantino, L. M., Flórez, J. C., Benavides Machado, P., \& Bacca, T. (2011). Minador de las hojas del cafeto: Una plaga potencial por efectos del cambio climático. Avances Técnicos Cenicafé, 409, 1-12. http://hdl.handle.net/10778/330

Constantino, L. M., Gil-Palacio, Z., Benavides Machado, P., Martínez, H., Giraldo-Jaramillo, M., \& Villegas G., C. (2013). Otros habitantes naturales del cafetal. En Federación Nacional de Cafeteros de Colombia (Ed.), Manual del cafetero colombiano: investigación y tecnología para la sostenibilidad de la caficultura (Vol. 2, pp. 261-306). Cenicafé.

Centro Nacional de Investigaciones de Cáfe. (2011). Informe anual Cenicafé 2011. https://www.cenicafe. org/es/publications/Informe anual completo.pdf

Centro Nacional de Investigaciones de Cáfe. (2014). Informe anual Cenicafé 2014. https://www.cenicafe. org/es/publications/informeAnualCenicafe2014.pdf

Constantino, L.M., \& Benavides Machado, P. (2017). Diagnóstico del daño por gusano trozador Spodoptera latifascia (Lepidoptera: Noctuidae) en cultivos de café en levante en el Municipio de Sevilla, Valle [Informe Técnico - Disciplina de Entomología]. Cenicafé.

Constantino, L.M., Benavides Machado, P., Escobar, S., \& Armbrecht, I. (2017). Capacidad depredadora de hormigas sobre Hypothenemus hampei (Coleoptera: Curculionidae) en condiciones de campo [Resumen de Congreso 44]. Sociedad Colombiana de Entomología.

Constantino, L.M., Cadena, O., Cardona, J.M., Benavides Machado, P., Góngora, C. E. (2018). A new Colombian pest species of the genus Poecilocloeus Bruner (Orthoptera: Acrididae: Proctolabinae) on coffee, with a key to the Neotropical species. Insecta Mundi, 621, 1-25. https://journals.flvc.org/mundi/article/view/0621

Coto, D., Saunders, J. L. 2004. Insectos plaga de cultivos perennes con énfasis en frutales en América Central. Turrialba, C.A. CATIE. http://hdl.handle.net/11554/2549

David-Rueda, G., Constantino, L. M., Montoya, E. C., Ortega, O. E., Gil Palacio, Z. N., \& Benavides Machado, P. (2016). Diagnóstico de Leucoptera coffeella (Lepidoptera: Lyonetiidae) y sus parasitoides en el departamento de Antioquia, Colombia. Revista Colombiana de Entomología, 42(1), 4-11. https://doi. org/10.25100/socolen.v42i1.6662

DeBach, P. (1964). Biological Control of Insect Pests and Weeds. Reinhold Publishing Corporation.

DeBach, P., \& Rosen, D. (1991). Biological Control by Natural Enemies (2nd ed.). Cambridge University Press.

Follett, P. A., Kawabata, A., Nelson, R., Asmus, G., Burt, J., Goschke, K., Ewing, C., Gaertner, J., Brill, E., \& Geib, S. (2016). Predation by flat bark beetles (Coleoptera: Silvanidae and Laemophloeidae) on coffee berry borer (Coleoptera: Curculionidae) in Hawaii coffee. Biological Control, 101, 152-158. https:/l doi.org/10.1016/j.biocontrol.2016.07.002

Fragoso, D. B., Guedes, R. N. C., Picanço, M. C., \& Zambolim, L. (2002). Insecticide use and organophosphate resistance in the coffee leaf miner Leucoptera coffeella (Lepidoptera: Lyonetiidae). Bulletin of Entomological Research, 92(3), 203-212. https://doi.org/10.1079/BER2002156

Fragoso, D. B., Guedes, R. N. C., \& Ladeira, J. A. (2003). Selection in the evolution of resistance to organophosphates in Leucoptera coffeella (Guérin-Mèneville) (Lepidoptera: Lyonetiidae). Neotropical Entomology, 32(2), 329-334. https://doi.org/10.1590/S1519-566X2003000200020 
Gallego, M. C., \& Armbrecht, I. (2005). Depredación por hormigas sobre la broca del café Hypothenemus hampei (Coleoptera: Scolytinae) en cafetales cultivados bajo dos niveles de sombra en Colombia. Revista Manejo Integrado de Plagas y Agroecología, 76, 32-40. http://www. sidalc.net/repdoc/A1859E/A1859E.PDF

Gauld, I., \& Bolton, B. (1996). The Biology of the Hymenoptera. In I. Gauld \& B. Bolton (Eds.), The Hymenoptera (pp. 8-39). Oxford University Press.

Gil-Palacio, Z., Constantino, L. M., Martínez, H., \& Benavides Machado, P. (2013). Aprenda a manejar la arañita roja del café. Avances Técnicos Cenicafé, 436, 1-8. http://hdl.handle.net/10778/473

Gil-Palacio, Z., Benavides Machado, P., \& Constantino, L. M. (2016). Hemiptera: Coccoidea de las raíces del café y sus parasitoides en el Valle del Cauca. Revista Cenicafé, 67(1), 73-80. http://hdl.handle.net/10778/680

Giraldo-Jaramillo, M., Galindo-Leva, L.A., Benavides Machado, P. (2011). La arañita roja del café. Biología y hábitos. Avances Técnicos Cenicafé, 445, 1-8. http://hdl.handle.net/10778/395

Godfray, H. C. J. (1994). Parasitoids: Behavioural and Evolutionary Ecology. Princeton University Press.

Greathead, D. J. (1986). Parasitoids in classical biological control. In J. Waage \& D. Greathead. (Eds.), Insect Parasitoids (pp. 289-318). Academic Press.

Holloway. J. D., Bradley, J. D. \& Carter, D. J. (1987). CIE Guides to Insects of Importance to Man. I. Lepidoptera. CAB International Institute of Entomology.

Jaramillo, J. (2008). Biology, ecology and biological control of the cofee berry borer, Hypothenemus hampei (Ferrari) (Coleoptera: Curculionidae: Scolytinae). [Tesis de Doctorado]. Gottfried Wilhelm Leibniz Universität Hannover.

Jaramillo, J., Borgemeister, C., \& Setamou, M. (2006). Field superparasitism by Phymastichus coffea, a parasitoid of adult coffee berry borer, Hypothenemus hampei. Entomologia Experimentalis et Applicata, 119(3), 231-237. https://doi.org/10.1111/j.1570-7458.2006.00413.x

King, A. B. S., Saunders, J.L. (1984). The invertebrate pests of annual food crops in Central America: a guide to their recognition and control. Overseas Development Administration.

Laiton, L. A., Constantino, L. M., \& Benavides Machado, P. (2018). Capacidad depredadora de Cathartus quadricollis y Ahasverus advena (Coleoptera: Silvanidae) sobre Hypothenemus hampei (Coleoptera: Curculionidae) en laboratorio. Revista Colombiana de Entomología, 44(2), 200-205. https://doi.org/10.25100/ socolen.v44i2.7319

Larsen, T., Escobar, F., \& Armbrecht, I. (2012). Insectos de los Andes tropicales: Patrones de Diversidad, Procesos y Cambio Global. En S, Herzog., R. Martínez., P. Jorgensen \& H. Tiessen (Eds.), Cambio Climático y Biodiversidad en los Andes Tropicales (pp. 265-286). Instituto Interamericano para la investigación del Cambio Global (IAI); Sao José dos Campo; Comité Científico sobre Problemas del Medio Ambiente (SCOPE). http://www. iai.int/es/post/detail/cambio-climatico-y-biodiversidad-en-los-andes-tropicales

Le cato, G. L., \& Davis, R. (1973). Preferences of the predator Xylocoris flavipes (Hemiptera: Anthocoridae) for species and instars of stored-product insects. Florida Entomologist, 56(1), 57-59. https://journals. flvc. org/flaent/article/view/56764

Lomeli-Flores, R. (2007). Natural enemies and mortality factors of the coffee leafminer Leucoptera coffeella (Guérin-Ménèville) (Lepidoptera: Lyonetiidae) in Chiapas, Mexico. [Tesis de Doctorado], Texas A\&M University. http://hdl.handle.net/1969.1/ETD-TAMU-2073

López-Núñez, J.C. (2008). Nematodos para el control de insectos plagas. En A. E. Bustillo Parley (Ed.), Los insectos y su manejo en la caficultura colombiana (pp. 150-183). Cenicafé. 
Maldonado, C. E., \& Benavides Machado, P. (2011). Diferenciación genetica y biológica del parasitoide de la broca del café, Prorops nasuta, en Colombia. Revista Cenicafé, 62(2), 41-57. http://hdl.handle. net/10778/481

Myers, N., Mittermeier, R. A., Mittermeier, C. G., Da Fonseca, G. A. B., \& Kent, J. (2000). Biodiversity hotspots for conservation priorities. Nature, 403(6772), 853-858. https://doi.org/10.1038/35002501

Nicholls, C. I. (2008). Control biológico de insectos: un enfoque agroecológico. Editorial Universidad de Antioquia.

Noyes, J.S. (1995). Encyrtidae of Costa Rica (Hymenoptera: Chalcidoidea); the genus Aenasius Walker, parasitoids of mealybugs. Bulletin of the Natural History Museum 64(2), 117-163.

Núñez B., L., Gómez S., R., Guarín, G., \& León, G. (2004). Moscas de las frutas (Diptera: Tephritidae) y parasitoides asociados con Psidium guajava y Coffea arabica en tres municipios de la Provincia de Vélez (Santander, Colombia). Parte 1. Índices de infestación y daño por moscas de la fruta (Diptera:Tephritidae). Revista Ciencia \& Tecnología Agropecuaria Corpoica 5(1), 5-12. https://doi.org/10.21930/rcta.vol5 num1 art:16

Paredes, D., Campos, M., \& Cayuela, L. (2013). El control biológico de plagas de artrópodos por conservación: Técnicas y estado delarte. RevistaEcosistemas, 22(1), 56-61. https://www.revistaecosistemas. net/index.php/ecosistemas/article/view/766

Pérez-Lachaud, G., \& Hardy, I. C. W. (1999). Reproductive Biology of Cephalonomia hyalinipennis (Hymenoptera: Bethylidae), a Native Parasitoid of the Coffee Berry Borer, Hypothenemus hampei (Coleoptera: Scolytidae), in Chiapas, Mexico. Biological Control, 14(3), 152-158. https://doi.org/10.1006/ $\underline{\text { bcon. } 1998.0685}$

Philpott, S. M., \& Armbrecht, I. (2006). Biodiversity in tropical agroforests and the ecological role of ants and ant diversity in predatory function. Ecological Entomology, 31(4), 369-377. https://doi.org/10.1111/ j.1365-2311.2006.00793.x

Pogue, M. G. (2002). A world revision of the genus Spodoptera Guenee (Lepidoptera: Noctuidae). [Memorias de Congreso 43]. American Entomological Society.

Quezada, J. R., Rodríguez, A. (1989). Brote de larvas de Rotschildia orizaba (Lepidoptera: Saturnidae) en café, una experiencia en manejo integrado de plagas. Manejo Integrado de Plagas (Costa Rica), 12, 21-32. http://hdl.handle.net/11554/5840

Quimbayo, N., Serna, F., Olivares, T., Angulo, A. (2010). Nóctuidos (Lepidoptera) en cultivos de flores colombianas. Revista Colombiana de Entomología, 36(1), 38-46. http://www.scielo.org.co/pdf/rcen/v36n1/ v36n1a08.pdf

Robinson, G.S., Ackery, P.R., Kitching, I.J., Beccaloni, G.W., Hernández, L.M. (2010). HOSTS - A Database of the World's Lepidopteran Hostplants [Database record]. Natural History Museum. http://www. nhm.ac.uk/hosts

Rodríguez-Pérez, M.A., Beckage, N.E. (2006). Estrategias co-evolutivas de la interacción entre parasitoides y polidnavirus. Revista Latinoamericana de Microbiología, 48(1): 31-43.

Segoli, M., Harari, A.R., Rosenheim, J.A., Bouskila, A., \& Keasar, T. (2010). The evolution of polyembryony in parasitoid wasps. Journal of Evolutionary Biology, 23(9), 1807-1819. https://doi.org/10.1111/j.14209101.2010.02049.x

Smith, S. M. (1996). Biological control with Trichogramma: advances, successes, and potential of their use. Annual Review of Entomology, 41, 375-406. https://doi.org/10.1146/annurev.en.41.010196.002111 
Souza, S. A. S., Resende, A. L. S., Strikis, P. C., Costa, J. R., Ricci, M. S. F., \& Aguiar-Menezes, E. L. (2005). Infestação natural de moscas frugívoras (Diptera: Tephritoidea) em café arábica, sob cultivo orgânico arborizado e a pleno sol, em Valença, RJ. Neotropical Entomology, 34(4), 639-648. https://doi. org/10.1590/S1519-566X2005000400015

Van den Bosch, R., \& Messenger, P.S. (1973). Biological Control. Intertext Educational Publisher.

Van den Bosch, R., \& Messenger, P. S., \& Gutiérrez, A. P. (1982). An introduction to biological control. Plenum Press.

Van Driesche, R.G., Hoddle, M.S., \& Center, T.D. (2007). Control de plagas y malezas por enemigos naturales. USDA; US Forest Service; USDA Forest Health Technology Enterprise Team.

Van Driesche, R., \& Bellows, T. S. (1996). Biological Control. Chapman and Hall.

Van Lenteren, J.C., Bueno, V.H. 2003. Augmentative biological control of arthropods in Latin America. BioControl, 48(2), 123-139.

Vinson, S.B. 1975. Biochemical coevolution between parasitoids and their hosts. In P.W. Price (Ed.), Evolutionary Strategies of Parasitic Insects and Mites (pp. 14-48). Springer US. https://doi.org/10.1007/978$1-4615-8732-3$

Vinson, S.B. 1981. Habitat location. In D.A. Nordlund, R.L. Jones, \& W.J. Lewis (Eds.), Semiochemicals: Their Role in Pest Control (pp.51-77). Wiley \& Sons.

Vera-Montoya, L., Gil-Palacio, Z., \& Benavides Machado, P. (2007). Identificación de enemigos naturales de Hypothenemus hampei en la zona cafetera central colombiana. Revista Cenicafé, 58(3), 185-195. http:ll hdl.handle.net/10778/144

Vega, F. E., Infante, F., Castillo, A., \& Jaramillo, J. (2009). The cofee berry borer, Hypothenemus hampei (Ferrari) (Coleoptera: Curculionidae): a short review, with recent findings and future research directions. Terrestrial Arthropod Reviews, 2, 129-147.

Vélez, R. (1997). Agrotis ipsilon. En Plagas agrícolas de impacto económico en Colombia: bionomía y manejo integrado (pp. 220-225). Editorial Universidad de Antioquia.

Vélez-Hoyos, M., Bustillo, A. E., \& Posada, F. J. (2006). Depredación de Hypothenemus hampei por hormigas, durante el secado solar del café. Revista Cenicafé, 57(3),198-207. http://hdl. handle.net/10778/138

Waage, J. K., \& Greathead, D. (1986). Insect Parasitoids. Academic Press, London.

Como citar:

Constantino, L. M. (2020). El control biológico natural. En P. Benavides Machado \& C. E. Góngora (Eds.), El Control Natural de Insectos en el Ecosistema Cafetero Colombiano (36-67). Cenicafé. https://doi. org/10.38141/10791/0001 3 